\title{
The Development of Deep Brain Stimulation for Movement Disorders
}

\section{Ray Greek ${ }^{1 *}$ and Lawrence A. Hansen ${ }^{2}$}

${ }^{1}$ Americans for Medical Advancement, 2251 Refugio Rd, Goleta, CA 93117, USA

${ }^{2}$ Professor of Neuroscience and Pathology, Department of Neurosciences, University of California, San Diego, Mail Code 062, 9500 Gilman Drive (MTF 351), La Jolla, CA 92093-0624, USA

\begin{abstract}
The development of deep brain stimulation has revolutionized care for patients with movement disorders like Parkinson's disease. Many areas of science contributed to this technology but one area, the use of animal models, has been cited as vital. We review these claims as well as the history of the discoveries that eventually led to deep brain stimulation in an attempt to ascertain: 1) the contributions of animal models; 2) the contributions from humanbased research and observation; and the role of advances in the engineering, physics, and computer science. We distinguish between advances and discoveries that were, or at least appear to be, dependent on animal models and those where animals were involved but that could have occurred, and/or were occurring simultaneously, with humanbased research. We conclude that animal-based research played a role in defining gross anatomy in the $19^{\text {th }}$ and early $20^{\text {th }}$ centuries, but that essentially all subsequent advances were human-based or secondary to advances in the physical and applied sciences. This has historical, funding, and ethical implications as the development of deep brain stimulation is cited as an example of the importance of animal-based research and a reason for continued social and financial support of animal models in general as opposed to clinical research, other human-based research modalities, and the various disciplines of the physical and applied sciences.
\end{abstract}

Keywords: Animal models; Deep brain stimulation; Ethics; Funding; Human-based research; Medical history

\section{Introduction}

Deep brain stimulation (DBS) is a technique used to alleviate abnormalities of motor function such as tremor, rigidity, and dyskinesia that occur secondary to diseases such as Parkinson's disease (PD), Multiple sclerosis (MS), dystonia, and seizure disorders. Collectively, these conditions and diseases are referred to as Movement disorders (MDs). DBS is also being investigated for use in neuropsychiatric disorders. To place the electrode for DBS, a burr hole in the skull is created, an electrode is placed through the burr hole into a specific location in the brain, and subsequently electrical stimulation is relayed down the electrode. Areas of the brain subject to stimulation with DBS include the Ventral intermediate nucleus (Vim) of the thalamus and structures in the Basal ganglion (BG) such as the Subthalamic nucleus (STN) and the Globus pallidus (GP) including the Globus pallidus interna (GPi). The STN and GPi are targets for PD while the Vim is targeted for essential tremor. As of 2010, greater than 80,000 patients worldwide had been treated with DBS [1].

\section{Materials and Methods}

We surveyed the available English language scientific literature in order to assess the role of animal models in the development of DBS. We also surveyed both the lay and science literature in order to ascertain what position society in general, primarily in the US and Europe has regarding animals in research.

\section{Results}

There is both a recent and more dated history relevant to claims made for the development of DBS. In 1976, a graduate student in chemistry synthesized MPPP (1-Methyl-4-phenyl-4-propionoxypiperidine), an opioid [2], that was contaminated with MPTP (1-methyl-4-phenyl1,2,3,6-tetrahydropyridine). Several days after using the drug, he, along with his friends who also experimented with the drug, developed Parkinsonism [3]. MPTP is not toxic; however, it is metabolized to MPP+ (1-methyl-4-phenylpyridinium), which selectively kills cells in the substantia nigra (SN) of humans. This was confirmed several months later on autopsy after the same graduate student overdosed on cocaine. Rats were initially tested with MPTP, but toxicity was not observed [4,5]. In 1982, more human cases of MPTP toxicity appeared and this led to testing MPTP on monkeys and the discovery that MPTP also caused Parkinsonism in monkeys [6]. Monkeys were then used as models of PD as well as MDs in general [7]. These MPTP monkey studies are credited, explicitly as well as implicitly, for being responsible for the development of DBS [8-16] (also see below).

The fact that clinical observation and past research is dismissed as unimportant by animal modelers is illustrated by the neuroscientist Ringach:

How was the method [DBS] developed? Back in 1983, Langston and colleagues reported on a clinical case study of four patients that developed Parkinsonism after illicit drug use. Analyses of the drugs they had taken via mass spectroscopy revealed primarily MPTP, but there were also traces of MPPP. They suggested MPTP might be the most likely culprit and suggested that: 'Given the pathologically studied case, the relative purity of the clinical syndrome seen in our patients, and its remarkable clinical resemblance to Parkinson's disease, the drug [MPTP] may be of value in producing an animal model of Parkinson's disease.' In other words, a group of clinicians studied a handful of human patient cases, identified a potential link

*Corresponding author: Ray Greek, Americans for Medical Advancement 2251 Refugio Rd, Goleta, CA 93117, USA, Tel: 805-685-6812; E-mail: DrRayGreek@gmail.com

Received August 14, 2012; Accepted September 28, 2012; Published October 04, 2012

Citation: Greek R, Hansen LA (2012) The Development of Deep Brain Stimulation for Movement Disorders. J Clinic Res Bioeth 3:137. doi:10.4172/21559627.1000137

Copyright: (C) 2012 Greek R, et al. This is an open-access article distributed under the terms of the Creative Commons Attribution License, which permits unrestricted use, distribution, and reproduction in any medium, provided the original author and source are credited. 
between MPTP toxicity and the development of PD, and proposed to follow up with animals [sic] studies [17].

Claims, both stated and implied, that the use of nonhuman animals (hereafter referred to simply as animals) in the 1800s and early 1900s were also necessary for the development of DBS are similarly put forth but are secondary to the claims made for the role of the MPTP monkeys [8-12]. We will explore the role that animal models of both eras played in the development of DBS. While the claim is usually made that DBS per se was made possible only by animal studies, this can be divided into three very specific claims, which are amenable for examination. In this paper, we explore the following claims regarding the development of DBS.

1. The claim that the early concepts of neuroanatomy were possible only because animals were studied in the 1800s and early 1900s and the related claim that the stereotactic device used for DBS procedures was first used on animals and could not have been invented without animals.

2. The claim that the knowledge of the thalamus, STN, the GP in general, and the GPi specifically are involved in MDs in general and PD in particular was determined from the MPTP monkey research.

3. The claim that the concept of lesioning, or disrupting with electrical stimulation, the STN and the GPi in order to alleviate motor disturbances, as well as the frequency at which to use DBS arose secondary to MPTP experiments on monkeys.

We will review the history of DBS claim by claim in order to determine what role animal models played in the development of DBS.

\section{Claim 1}

The claim that the early concepts of human neuroanatomy were possible only because animals were studied in the 1800s and early 1900s and the related claim that the stereotactic device was first used on animals and could not have been invented without animals.

In order to treat movement disorders originating in the brain, the functional anatomy of the brain must first be determined. As early as hippocrates, physicians were studying trauma patients and learning from these experiences. For example, hippocrates had demonstrated the principle that the contralateral side of the brain controls the motor function of the body. While removing bone fragments from the exposed brain of a boy, he gently stroked the brain with his fingernail. The boy convulsed on the side opposite the exposed brain $[18,19]$. Thus, the concept of contralateral control was at least suspected in ancient times, as was the notion that certain stimulations could activate the brain and cause movement.

Experiments on animals, including dogs and nonhuman primates (NHPs), were extensively performed in the $19^{\text {th }}$ century in an attempt to understand the human brain. Some of the results from these studies did have human correlates but others did not. For example, Marshall and Magoun [20] discuss the research of Ferrier and his unsuccessful attempts to superimpose brain mapping studies from animals to humans. Similarities on the gross level do exist among species, especially mammals; however, important differences become apparent on deeper examination. For example, Van Hooser discusses similarities and differences among species in the primary visual cortex and points out that:

There is considerable diversity in the abundance of different cell classes, laminar organization, functional architecture, and functional connectivity. Orientation-selective responses arise in different layers in different species. Some mammals have elaborate columnar architecture like orientation maps and ocular dominance bands, but others lack this organization with no apparent impact on single cell properties. Finally, local functional connectivity varies according to map structure: similar cells are connected in smooth map regions but dissimilar cells are linked in animals without maps [21].

Differences are like these; because they occur in evolved complex systems [22-30], have major implications for extrapolating among species [31-36].

In the mid 1800s, Jackson observed patients, conducted experiments on NHPs, and linked the basal ganglion to MDs [37]. Animal-human correlates like this have led Pereira and Aziz to describe research from the early 1900s in the following terms:

Nearly a century on from Parkinson's original description, soon after Wilson had described hepato-lenticular degeneration in the disease that came to bear his name [the 1912 article], Ramsey Hunt postulated a theory whereby lesions to different components of the basal ganglia could cause not only chorea, but also parkinsonism and athetosis [38]. His theory built on Wilson's findings from lesions made in primate basal ganglia and cerebral cortex using Horsley and Clarke's recently invented stereotactic apparatus.

It is worth taking a closer look at Wilson and Hunt's research. In 1912, Wilson [39] published his findings describing hepato-lenticular degeneration or Wilson's disease, now known to be caused by mutations in gene $A T P 7 B[40,41]$. Wilson's disease is caused by copper accumulation in the tissues, which results in damage to not only the liver and CNS but also the kidneys and eyes. The symptoms were well described from human observation, as were the signs, for example, movement disorders. Changes in the basal ganglia were described as early as 1890 , secondary to autopsies conducted by Ormerod and Homén, and again in 1907 by Wilson [39] who also conducted autopsies. Indeed, Wilson's 1912 paper is a classic example of humanbased research. Clearly, the main sources of and basis for Wilson's paper were human-based.

In Wilson's 1914 paper [42], he describes various animal-based studies involving the brain. One is impressed by the differences in results obtained by the numerous researchers that Wilson discusses. These differences are due in part to the studies being performed at different times and with different species. (We will examine the concept of species differences in more detail) Moreover, much improvement has been made in methodology and technology over the last century. We readily acknowledge that animal studies were ongoing in the 1800s and early 1900s and that some of these linked the basal ganglia to movement disorders. However, we must also point out that scientists came to very different conclusions regarding the exact function of neuroanatomy during the $19^{\text {th }}$ and early $20^{\text {th }}$ centuries, in part secondary to lack of sophisticated technologies but also in part due to inter-species variation. Importantly for this essay, Wilson's stereotactic studies on monkeys occurred after his 1912 paper. Hunt published his findings in 1917 [38]. Hunt's article is clinical, humanbased research with autopsies again revealing pathology in the basal ganglia. While Hunt cites animal studies, they are very few in number and the reasoning for his hypothesis was based primarily on human findings.

Otfrid Foerster (1873-1941) was a German neurosurgeon who 
contributed much to the field of neurosurgery and neuroscience. $\mathrm{He}$ pioneered the procedures of rhizotomy and anterolateral cordotomy, described dermatomes, and performed the first electrocorticogram of a brain tumor $[43,44]$. He also hypothesized that the GP was involved in MDs. In coming to this conclusion, he studied both humans and animals [45]. Tan and Black state of Foerster: "A provisional hypothesis would be tested clinically during surgery and then neurophysiologically on the patient. If the hypothesis could not be tested on a human subject, the condition was reproduced on an experimental animal and then investigated" [44]. Foerster was a unique individual in the history of neurosurgery and, as the above quote indicates, appears to have learned much from the patients he operated on. Foerster's approach illustrates the state of affairs during that era. Human-based research and animalbased research occurred simultaneously with the same procedures frequently being performed on both [45]. To separate exactly which discoveries were dependent on animals and which were human-based would be essentially impossible given the fact that the literature was not published with this goal in mind and the participants are dead. A theoretical case can be made that all anatomical knowledge necessary for operating on the BG to control MDs could have come from ethically conducted human-based studies. However, such is not the purpose of this analysis.

As scientists learned that neural tissue relied on electrical impulses for the transmission of information, the possibility of interrupting transmission via the implantation of electrodes was raised. The first recorded instance of electrical impulses being applied to the living brain appears to be in the 1800s and cats were the subjects [46]. Over the years, various animal species were used to demonstrate that when electrical current is applied to the brain, movement as well as other actions could be produced or inhibited.

Victor Horsley was another surgeon-scientist who contributed much to the subject of neuroanatomy. For example, he studied brains from humans ranging in age from fetuses to 111 years and published a map of surface changes that occurred during this time [47]. Horsley realized the importance of precision in determining the function of the brain and this inspired him to develop the stereotactic apparatus [48]. Until the mid-twentieth century, surgeries were performed on an open brain with a free hand hence, would be considered in exact by today's standards. This suboptimal situation improved dramatically with the introduction of the stereotactic device. The stereotactic device was undeniably first developed on animals circa 1906 by Horsley and Clarke but, interestingly, was not routinely used in human surgery for several decades. Clarke, who was not a physician, suggested to Horsley that the stereotactic device could be used in humans but Horsley rejected the idea and the ensuing rift apparently ended their friendship [49]. Horsley contributed much to the field of neuroscience and outlined general principles that were shown to apply among species [50,51] but he rejected the notion that stereotactic technology should be applied to humans.

Redesigning the stereotactic device for humans proved difficult because of the variations among humans in the relationship between the skull and the cortical structures. The routine use of the stereotactic device in humans was made possible by Dandy's invention of ventriculography [49]. Spiegel and Wycis pioneered the use of the stereotactic device-the stereoencephalotome-in 1947 [52-60]. Spiegel designed his stereotactic device based on that of Horsley and Clarke $[48,61,62]$ then developed a mapping system based on ventriculography. Spiegel et al. performed the first pallidotomy and thalamotomy using the stereotactic device $[55,59,60]$. Other surgeons developed or revised the stereotactic device based on experience with patients, ultimately resulting in the designs we currently use. Discussing Spiegel and Wycis, Gross et al. state:

they deserve indisputable credit for elaborating the main prerequisites of the new method: the first modern stereotactic apparatus: the first stereotactic atlas of the human brain and the first surgical demonstration of this new technique, a pallidotomy carried out in 1948 on a patient with Huntington's chorea. The choice of pallidum was justified by the argument that, the pallidum being the output structure of the extrapyramidal motor system, it must be destroyed in order to stop the irritation' or 'excessive activity' of neural pathways, a concept developed during the 1930s [63].

Note that the first time the device was used it was to operate on the BG for MDs. While we will expand on this momentarily, it is already clear that the BG was associated MDs long before the MPTP monkey experiments of the 1980s.

The stereotactic device is a mechanical device engineered for a purpose. Horsley and Clarke deserve recognition for being the first to think of using the device the way they did. After Dandy's demonstration of ventriculography however, the need for a means of stabilizing the human skull and standardizing surgical techniques was a logical step. The stereotactic device was modified extensively for human use for treating disorders of the motor system based on anatomical knowledge gained from studying humans. We do not find tenable the notion that the stereotactic device, fundamentally a complicated clamp, could not have been developed without the use of animals. Development of the stereotactic device was dependent on straight forward engineering skills (how it was designed) and resources (what materials were suitable for construction), not animal models.

We should also note that some of the operations in the early $20^{\text {th }}$ century, and the experiments that took place during those operations, might not be considered entirely ethical today. Regardless, much was learned and in studying such history, it is difficult to separate what was learned from the lab and what was learned in the operating room. In many instances it appears the discovery could have just as likely come from one as the other. The articles of that era were not written with a view of separating the findings from animal studies from those of human studies. In terms of claim \#1, we conclude that much was learned about neuroanatomy in general from studying animals; however, much that was learned did not translate to humans and much was learned independent of animal studies. We do not think the claim that animals were necessary for early neuroanatomy advances can be substantiated. History is murky and we believe there is little to be gained by arguing what is essentially ancient history in terms of medical science. Further, as the real debate surrounding DBS lies elsewhere, we will not consider claim \#1 any longer. We close this section by paraphrasing Shanks and Greek. This article:

is not intended to be a criticism of the use of animals in the context of basic biological research. There can be no doubt that careful studies of animals have prompted important hypotheses about basic biological principles, and there can be no doubt that studies of animals have contributed greatly to our scientific understanding of life, and there is little doubt that these studies will continue to illuminate these matters in the future [35].

\section{Claim 2}

The claim that the knowledge that the thalamus, STN, the GP in 
general, and the GPi specifically are involved in MDs in general and PD in particular was determined from the MPTP monkey research.

After MPTP was discovered to cause tremors in monkeys, the monkey model was explored and an increase in activity in the STN was noted. Lesioning or stimulating the STN abolished the MPTPinduced motor activity in the monkeys [64-66]. The claim that the use of DBS on the STN was the result of monkey experiments is based on these and similar experiments. For example, Pereira and Aziz stated in 2006: "In the early 1990s, it was shown that lesions made to the subthalamic nucleus of the basal ganglia in primates reversed the motor symptoms of MPTP induced Parkinsonism" [8]. Gross et al. are more direct: "Pallidotomy and thalamotomy were both carried out on human patients before being studied in animal models of PD. Subthalamotomy, on the other hand, was only proposed for human surgery once experimental results demonstrated the clinical interest of this procedure" [63].

Bergman et al. [64] were among the first to perform such operations on the STN. Brotchie et al. and others then reproduced the results $[67,68]$. Importantly for this examination of the history of DBS, Bergman et al. stated in 1990: "Although it is known that Parkinson's disease results from a loss of dopaminergic neurons in the substantia nigra, the resulting alterations in activity in the basal ganglia responsible for parkinsonian motor deficits are still poorly characterized" [64]. [Emphasis added.] We should take a moment here to examine exactly what Bergman et al. are stating as it will become important as we further examine the history of neuroanatomy and DBS. The fact that the activity in the BG was (and still is) poorly characterized was used as one reason to study the monkey model of PD and DBS intervention. While some authors state outright, and others simply imply, that the role of the BG in PD was unknown in the 1980s, others make the claim that in order to develop DBS, more had to be known regarding the mechanisms of MDs, how these mechanisms affected the BG, and how DBS reversed these effects. As we will see, the mechanisms for DBS are still controversial yet much progress has been made in using DBS to treat MDs. Delineating the mechanisms of DBS is part of a broader controversy over mechanisms in general that we will address in a later section. For current purposes however, we will focus on the claim that the MPTP monkey model was necessary in order for neurosurgeons to consider using DBS on the STN and GPi.

Consider the following statements regarding the importance of the MPTP monkey studies. Limousin et al. stated in 1995:

In monkeys rendered parkinsonian, lesions and electrical stimulation of the subthalamic nucleus reduce all major motor disturbances. The effect of electrical stimulation of the subthalamic nucleus was assessed in three patients with disabling akineticrigid Parkinson's disease and severe motor fluctuations. . . This is the first demonstration in human beings of the part played by the subthalamic nuclei in the pathophysiology of Parkinson's disease [69]. [Emphasis added]

Limousin et al. stated in 1999:

STN stimulation is based on studies done in the monkey model of Parkinson's disease. In these monkeys, an overactivity of the STN is found and lesions or electrical stimulation improve parkinsonian features. Therefore, STN stimulation was applied to patients with idiopathic Parkinson's disease [70]. [Emphasis added]

Clearly, Limousin et al. are claiming a causal relationship between the monkey studies and the use of DBS on the STN.
Bergman et al. continue:

Recently, increased activity in the subthalamic nucleus has been implicated in the motor abnormalities. To test this hypothesis, the effects of lesions of the subthalamic nucleus were evaluated in monkeys rendered parkinsonian by treatment with 1-methyl-4phenyl-1,2,3,6-tetrahydropyridine (MPTP). The lesions reduced all of the major motor disturbances in the contralateral limbs, including akinesia, rigidity, and tremor. This result supports the postulated role of excessive activity in the subthalamic nucleus in Parkinson's disease [64]. [Emphasis added.]

Here Bergman et al. are clearly stating that studies on the monkey model were responsible for linking the STN to PD. The above statements are not subtle, nor, as we will show, are they consistent with history. Obeso et al., based on the research by Bergman and others, decided that subthalamotomy might be beneficial to patients with PD [71,72]. Gross et al. summarize:

These advances had been made possible by the development of animal models of PD using selective neurotoxins to destroy the SNc. The myriad studies carried out to elucidate the pathophysiological mechanisms underlying the evolution of PD had allowed the elaboration of a hypothetical schema for the functional organization of the motor circuit, both for the normal and for the parkinsonian state, linking the cortex, the basal ganglia, and the thalamus [63] [Emphasis added]

As we will show, such had been hypothesized for humans in the 1920s and 1930s and had been demonstrated in humans in the 1950s. There was really nothing new, that was clinically relevant, that was learned about human neuroanatomy from the monkey studies of the 1980s and 1990s. Cooper and others did not understand the complete anatomy of movement disorders, indeed we do not fully understand it today, yet they operated on and or stimulated the same areas neurosurgeons do today.

\section{Pereira and Aziz state:}

It was not until the 1980s when data had been gathered from several years' worth of studies of single neuron activities in awake, moving primates that a theory for basal ganglia function could be postulated that could explain the symptoms and signs of PD and other movement disorders.... Within the past two decades, much research has been conducted towards elucidating the roles of the basal ganglia in $\mathrm{PD}$, other movement disorders, and psychiatric illnesses [8].

Actually, Pereira and Aziz mean hypothesis not theory [73-75]. Their misuse of scientific terminology notwithstanding, the animal model community continues to emphasize the need to use monkeys to find the mechanisms by which DBS is effective in the STN and elsewhere. Pereira and Aziz continue:

Current anatomical models of basal ganglia function. . . fail to explain wholly the efficacy of DBS in PD, in particular the finding that stimulation of the globus pallidus interna paradoxically improves dyskinesias without deleterious effects upon motor function, although primate research continues to further our knowledge in this regard [8].

The exact mechanisms by which DBS in the basal ganglia relieves movement disorders are still unknown, as is the exact nature of interactions within the basal ganglia and with the rest of the brain. 
Unquestionably, mechanisms are important. However, as we will explore in a later section, there are many drugs on the market today the mechanisms of which science does not understand. Further, the mechanism of DBS is of secondary importance to the fact that, as we will show, DBS was well established clinically to be effective long before the MPTP monkeys were used in research. Finally, as we will discuss, just because one discovers the mechanism of a treatment or disease in an animal model does not mean the mechanism is the same in humans. The cause of tremor in the MPTP monkeys is drug induced whereas the cause of Parkinsonism in humans is largely unknown. The time span for creating the lesion in the $\mathrm{SN}$ in monkeys is very short whereas it takes years for the disease to develop in humans. The mechanisms for tremor may very well differ, just as the mechanisms for cancer differ among species. As Alexander et al. pointed out in 1986 [76], there are differences between human and nonhuman primate brains:

That there may be additional basal ganglia-thalamocortical circuits, beyond those proposed here seems likely. This question can only be answered, however, by further anatomical and functional studies. Considering the enormous expansion of the frontal lobes in man and the selective targeting of basal ganglia influences on these frontal areas, it is even possible that circuits exist in man for which there are no counterparts in the monkey [76].

The fact that all of these perturbations are occurring in systems that are differently complex is also highly relevant $[31,32,35,36,77]$.

Treating MDs dates back to the $19^{\text {th }}$ century and Horsley was among the first to perform surgical intervention in an attempt to treat MDs. He developed a technique for removing the precentral gyrus in order to treat MDs and various surgeons performed this operation into the 1920 s [78-80]. As early as 1890 , Horsley $[81,82]$ was performing cortical ablations for athetosis. During this same era, at least two surgeons used intra-cortical alcohol injections to treat MDs [83-85]. Numerous brain and spinal cord procedures were attempted in the early $20^{\text {th }}$ century in efforts to control MDs [86]. Surgery on the thyroid was even tried [86]. To a large extent, this appears to have been a time of trial and error. As Laitinen stated: "When one sets out to make a historical survey of surgical attempts to relieve the tremor and rigor in Parkinson's disease, one cannot help feeling that it would have been a far easier task to list those nervous structures which have not been attacked" [87].

In 1927, Spatz [88] hypothesized that a system outside the traditional motor system existed and that this system was important in MDs. He proposed the concept of the extrapyramidal motor system. He also stated that the STN, SN, the pallidum, and other structures be placed into this category and linked this system to MDs [63]. Spatz was influenced in his thinking by multiple studies and observations, some of which appear to have been performed on animals. (As most of this research was published in German, it is difficult to say with certainty exactly which advance came from which species, but human studies and observations were also strong influences for Spatz.) Regardless of what influenced Spatz' thinking the most, the STN and pallidum had been linked to MDs in the 1920s, long before the MPTP monkey studies. The above claims that without the MPTP monkey experiments the STN would not have been linked to PD and we would never had applied DBS to the STN are thus false. Based on Spatz's work alone, we can confidently conclude that the 1980s MPTP monkey experiments did not reveal any vital new knowledge in terms of linking movement in PD to the STN. Determining which parts of the basal ganglia are involved in which motions disorders is still, as we will see, largely a matter of trial and error, brain mapping in humans being the most effective modality.

Despite the fact that in the 1920s Spatz proposed that the STN and $\mathrm{SN}$ were involved in MDs, the basal ganglion was considered off limits to surgeons into the 1930s. Dandy had observed patients that had suffered a stroke in this region and declared the area should not be operated on [89]. Gabriel and Nashold state: "At that time, the basal ganglia were regarded as surgical noli me tangere, part of an area asserted by Dandy as 'the center of consciousness' " [86]. Bucy also advocated for a handsoff approach to the region thinking that paralysis would surely result from such operations [90]. Clearly the basal ganglion was known to be involved in MDs as early as the 1920s and 1930s.

However, Bucy did perform a series of operations on the cortex during this time [91,92]. Bucy based these forays on previous reports of surgical successes and experimental work [86]. Wilson [39,93] believed the treatment for MDs was to be found in the "rolandic area" of the brain, also known as the central sulcus. Bucy would stimulate the area of the brain thought to be involved in the MD then excise it [94]. The operations did result in dramatic improvement or even abolition of the MD but the patients suffered side effects such as seizures and paralysis. We should here also point out that stimulation was linked to movement again in the 1930s. Gabriel and Nashold discuss a breakthrough in MDs made by Bucy:

In one of the cases, Bucy and Case made the interesting observation that large doses of barbiturates administered in preparation for encephalography abolished the involuntary movements for several hours after awakening. Based on the evidence that barbiturates were more depressant to the electrical excitability of Area 6 than to that of Area 4, Bucy thought that this observation supported his original hypothesis that the parapyramidal system was more concerned with producing athetosis [86].

Moreover, the BG was further confirmed to be involved in MDs through clinical experience. Meyers, in 1939, successfully excised the head of the caudate nucleus in a patient with Parkinson's disease. The operation abolished the tremor without adverse side effects. This was the first successful foray into the BG [95]. In 1951, Meyers published his series of operations for MDs [96]. He performed 58 operations on the BG before 1949 [97]. Kopell et al. commented on this:

Contemporary movement disorder neurosurgery evolved from empirical observations in patients with movement disorders undergoing lesions placed in various regions of the neuraxis. The basal ganglia have been a target for neuromodulation surgery since Russell Meyers' pioneering works in the late 1930s. Under the hypothesis that abnormal movements were mediated by the neopallidum, Meyers extirpated the anterior two-thirds of the head of the caudate through an anterior transventricular approach [98].

Meyers was aware of the notion that the BG was involved in MDs and of the fact that Browder, while performing a frontal lobectomy, had accidently lesioned the caudate. After Browder's patient recovered from anesthesia, Browder observed that the patient's tremor had ceased [86,99-101]. Meyers [95,102] operated on other structures in the GP including, "the head of the caudate nucleus and part of the capsula internal, the putamen, the pallidum and the ansa lenticularis. Both tremor and rigidity were partially improved. His work is interesting for this reason. Here was clinical evidence that a section of the pallidofugal pathway reduces or even eliminates rigidity as well as tremor" 
[63]. Thus by 1940 the globus pallidus and STN had been linked to movement disorders and operations performed on the BG in order to alleviate MDs [86,103]. Gabriel and Nashold state: "The importance of Meyer's data was that tremor could be abolished and rigidity reduced without the production of paresis, spasticity, or dyspraxia" [86]. Browder and others also treated MDs by operating on the BG during this time $[86,99,100,104]$. Thus the claim that the BG in general was only linked to MDs by experiments with moneys in the 1980s is false.

Serendipity often plays an important role in medical and surgical advances and the role of the BG in MDs would be further substantiated by serendipity. In 1953, Cooper was performing a craniotomy on a patient suffering from $\mathrm{PD}$, when he inadvertently tore the anterior choroidal artery $[105,106]$. Cooper tied off the artery and closed the incision without performing the planned pedunculotomy. When the patient awoke from anesthesia, his tremor was almost completely gone as was the rigidity but his strength remained intact. Cooper reported on eight cases with similar results [106] but eventually abandoned the operation secondary to variability in the distribution of the artery [46].

According to Gabriel and Nashold, Cooper was influenced by the research of A. A. Abbie on the blood supply for the basal ganglia, in determining that the area that had been infarcted "was the globus pallidus and its afferent connections through the ansa lenticularis with the corpus subthalamicum, ventrolateral nucleus of the thalamus, substantia nigra, and red nucleus" [86]. Abbie's articles [107,108] focused on human anatomy but also described anatomy in animals. In fact, Abbie compared and contrasted the blood supply of the brain among species, noting inter-species differences. The relevant portions of these papers for our discussion came from autopsies conducted by Abbie and other human-based research that Abbie references. Clearly, human-based research was responsible for determining the blood supply for the human BG. Thus by the mid-1950s more evidence that the GP and STN specifically were involved in MDs, including PD, had been accumulated [109].

Cooper's discovery led to the injecting of local anesthetic and alcohol into the GP and ablation by thermocoagulation. Cooper would inject local anesthetic into the GP in part as a screening technique to see which patients would respond to ablation via ligation of the anterior choroidal artery. He would also inject alcohol in order to accomplish neuroablation. He found rigidity and tremor markedly reduced in most patients, but rigidity more so than tremor [110,111]. Cooper performed chemopallidotomy for a number of different MDs [86]. On conducting an autopsy, Cooper discovered the lesion was actually in the thalamus and therefore switched to lesioning the ventrolateral nucleus of the thalamus $[112,113]$

By the early 1960s, thalamotomy using a stereotactic device had replaced Cooper's previous operation [46,106,114]. Gabriel and Nashold in 1998:

Between 1952 and 1962, Cooper and his colleagues performed 2210 consecutive basal ganglia procedures for the relief of involuntary movement disorders. Of these, 2060 were performed for relief of tremor and rigidity of Parkinson's disease and the rest for other dyskinesias. Among patients undergoing 735 chemopallidectomies, $60 \%$ obtained relief of tremor and $75 \%$ obtained relief of rigidity. Among patients undergoing 1170 chemothalamectomies, 80 and $85 \%$ were relieved of tremor and rigidity, respectively. The mortality rate was 2 to $3 \%$ for both procedures combined [86].

Cooper published a guide for lesioning the GP in order to treat MDs in 1960 [115]. The fact that Cooper published a guide to lesioning the
GP in order to treat MDs refutes claims that MPTP monkeys were responsible for linking the GP to MDs. Story et al. [116], Mundinger [117], and Fager [118] also successfully lesioned the STN in a large number of patients with PD. Clearly by the 1960s operations on very specific components of the basal ganglia were being performed for PD patients and the STN had been linked to movement disorders. No more data was needed before beginning to stimulate all areas of the basal ganglia.

Most of Cooper's work was human-based research and or observation and some of it might today be called human experimentation as Cooper, and others, were mapping out new territory. There were many failures and even today some of Cooper's contributions to neurosurgery are still controversial $[46,119]$. But his importance in the development of neurosurgery for movement disorders is not controversial. One cautionary lesson that can be learned from Cooper, that is relevant to our discussion, revolves around his use of animal data from Sherrington, Moruzzi, Dow, and others to justify his operation on the cerebellum to treat seizures and spasticity [46]. Blinded studies failed to show any benefit from this procedure [46]. Animals and humans have much in common in terms of how the brain functions and some are prone to cherry pick the commonalties in order to conclude that one can use data from animal models to predict human response. In order for a modality to be considered predictive in medical science however, it must demonstrate a very high positive predictive value and negative predictive value. When all the relevant studies concerning trans-species extrapolation are considered, animal models fail to be predictive modalities for humans in drug and disease research. Isolated instances of animals and humans sharing anatomical features are not the same as an animal model being predictive for humans in anatomy, pathophysiology, or drug response [31-36,77].

Simultaneously with Cooper, others were operating on the BG. In 1952, Spiegel and Wycis used the stereotactic device in an attempt to alleviate the tremor of PD [120]. They found that by interrupting signals from the pallidofungal via the ansa lenticularis the tremor subsided for several months without paralysis. They continued performing this operation and similar operations for a variety of MDs. Beginning in 1951, Narabayashi of Tokyo injected procaine in the GP of patients with PD [121-124]. Several neurosurgeons in France performed surgery on the basal ganglia using these or similar techniques $[63,125$ 130]. During the 1950s, surgery on the GP became more widespread $[86,131]$ but as Cooper's change to the thalamus became better known, more and more surgeons began performing operations on the thalamus as opposed to GP in order to treat PD.

Wolfson et al. describe the use of NHPs in research for MDs circa the late 1940s:

In 1949, Whittier and Mettler [132,133] demonstrated that lesions of the STN of monkeys produced hyperkinesia combined with choreiform and ballistic movements. The authors noted that destruction of $20 \%$ of the contralateral STN was necessary (less if the subthalamic fasciculus was involved) to produce the abnormal movement, whereas lesions of the internal segment of the globus pallidus, thalamic fasciculus, motor cortex, and lateral corticospinal tract reduced or abolished the movements [134].

The above is cited as an example of animal models being vital to linking MDs to the STN. However, as Wolfson et al. [134] discuss, MDs such as choreiform were described in the 1800 s by the physicians Charcot and Weir Mitchell and linked to the STN shortly thereafter: "Over 50 years ago, hemiballistic movements were noted to occur in patients 
with lesions (usually vascular) of the contralateral subthalamic nucleus (STN) [135,136]. Subsequently, this was confirmed by two large postmortem studies with human pathologic material" [137]

\section{Guridi and Obeso [138] echo the above:}

The prominent role of the subthalamic nucleus (STN) in the control of movement was suggested decades ago following the observation that its lesion induces hemiballism in man [136,139-142]. Several experimental studies, particularly those pioneered by Carpenter, Whittier, and Mettler, demonstrated the strict relationship between hemiballism and lesion of the STN in monkeys $[132,143]$.

Note the monkey studies were decades after the human studies. Even Parkinson himself had observed that when a patient suffered a stroke the tremor from his disease subsided only to return as the stroke resolved [144]. The relationship between the BG and MDs including PD was further substantiated in the 1950s. Bertrand states in 1957:

At any rate, it seems firmly established that there exists in the anterior and lower portion of the basal ganglia and the efferent fibres therefrom a center, an agglomeration, the destruction of which can eliminate the greater part of the symptoms of Parkinsonism without producing any permanent paralysis, if the section remains in front of the internal capsule [145].

Despite the history outlined above, the BG was almost forgotten as a treatment for MDs. Gross et al. [63] state the following about primate studies performed in the 1980s and 1990s:

Since the GPi is hyperactivated in PD, destroying the structure should release the thalamus and consequently alleviate parkinsonian motor abnormalities. Recent primate studies have considerably improved our knowledge of the somatotopic microanatomy of the different structures of the basal ganglia and highlighted the geographic segregation of the different circuits [146-150].

It is true that these primate studies refocused interest on the BG. This is a poor commentary on the way some scientists conduct animal-based studies, as a proper literature search would have revealed relevant human-based data. Obeso et al. 1997 acknowledge this stating:

The development of the core ideas concerning the pathophysiological basis of the parkinsonian syndrome coincided with the publication of Laitinen et al. in 1992. That paper reported 38 patients operated from 1985 to 1990 following Leksell's original concept of posteroventral pallidotomy. A dramatic improvement in rigidity and akinesia was described for all but one patient. Despite numerous methodological problems, which limited the interpretation of the data, this article fuelled the resurgence of pallidotomy for PD [72]. [Emphasis added.]

We will discuss Leksell et al. shortly. Pallidotomy was performed for years based on human studies and those same human studies or studies very similar to them also discovered that the STN and GP were involved in MDs. To claim that operations on the GP were dependent on monkey studies conducted in the 1990s is simply historically inaccurate. Further, with the development of small electrodes surgeons could and did place an electrode and stimulate the area with very little harm to the patient. Much was learned through this process of trial and error. This again, was an advance secondary to engineering. Bertrand and Martinez explain that the process of determining exactly where to lesion the brain was largely empirical:

The wide distribution of the center of these sections should be explained. The initial target was the ansa lenticularis and, after a few procedures, the globus pallidus. The lesions were very gradually made more posterior and slightly more mesial moving from the globus pallidus to the thalamus through the internal capsule on a purely empirical basis. A review of the results obtained after stimulation and section in two hundred consecutive cases indicates that tremor and rigidity can be alleviated by lesions within the mesial portion of the globus pallidus and, more specifically, the ventrolateral portion of the thalamus without any involvement of the cortico-spinal tract [151].

The use the stereotactic device greatly improved the accuracy of the operations and many surgeons used the device to treat MDs in the 1950s. Narabayashi, in Japan, used the stereotactic device to perform chemical pallidotomies on the anterodorsal section. Neurosurgeons performed the procedure based on the belief that an imbalance between the striatum and the pallidum was responsible for certain MDs [121,122] The results were disappointing [152]. In 1960, Gillingham et al. [153] published promising results from lesioning the area $3 \mathrm{~mm}$ behind the anterior commissure (AC). The location was chosen based on work by Spiegel and Wycis who had discovered a relationship between this location and the clinical outcome. Rigidity was relieved by lesioning an area 3-6 mm behind the AC while tremor was relieved by lesioning the area $9 \mathrm{~mm}$ behind the AC $[58,154]$. Also in 1960, Leksell's group (see below) published their results of posteroventral pallidotomies which extended all the way to the ansa lenticularis. This procedure was very successful, relieving both tremor and rigidity [131]. Pereira and Aziz: "That same decade, Leksell capitalised upon Cooper's discovery, using thermocoagulation together with his recently invented stereotaxic apparatus to accurately lesion the globus pallidus to ameliorate parkinsonian hypokinesia and rigidity in over 200 patients" [8].

Leksell's group in Sweden had operated on the GP in over 2000 patients in the 1950s and 1960s demonstrating dramatic improvements in rigidity and akinesia $[131,155,156]$. This definitive work was largely ignored after operations on the thalamus became popular, but was rediscovered after Laitinen et al. reproduced it in the early 1990s $[157,158]$. Gross et al. [63] state:

One of the reasons [the work by Leksell et al. received so little attention] could be that international attention was very much focused at the time on the work of the Freiburg school, which had moved the target site from the pallidum to the nucleus ventrolateralis (VL) of the thalamus on the strength of anatomical studies of the basal ganglia for which he had used the technique of retrograde cell tracing [159-162].

It appears the Freiburg school used both humans and animals in deciding to move their preferred site to the thalamus. As most of the articles are in German we are unable to determine exactly what role each species played in this transition. The move was unfortunate as Leksell was on the right track and had his example been followed we might have had relief for PD and other movement disorders much sooner. Leksell's work would not be rediscovered until 1992 with Laitinen et al. $[63,157,158]$. Laitinen and Hariz acknowledged the work of the Swedish group:

In 1960 Svennilson et al. reported that stereotactic lesions in the ventroposteromedial (VPM) pallidal region had abolished al cardinal symptoms of Parkinson's disease, i. e. tremor, rigor and bradykinesia and that the effect had lasted for 3.5 years at least [131]. At the time of this report neurosurgeons began to operate in the thalamus and this revolutionary pallidotomy report fell into oblivion. In 1985-88 we operated on 25 Parkinsonian patients in 
the VPM pallidum. The drugs were usually reduced by ca $50 \%$. Our study confirms the findings of Svennilson et al. VPM pallidotomy seems to have an equal and very good effect on tremor, rigor, bradykinesia, and L-dopa induced involuntary movements [163].

Laitinen et al. again stated in 1992:

The results presented here confirm the 1960 findings of Svennilson et al. that parkinsonian tremor, rigidity, and hypokinesia can be effectively abolished by posteroventral pallidotomy, an approach developed in 1956 and 1957 by Lars Leksell. The positive effect of posteroventral pallidotomy is believed to be based on the interruption of some striopallidal or subthalamopallidal pathways, which results in disinhibition of medial pallidal activity necessary for movement control [158] [See comments in [164].

Laitinen reinvented the procedure. Svennilson et al.:

From this point of view the cases fall into three main groups... Although all lesions have been located in the neighborhood of the pallidum, the site was deliberately varied between one case and another of the first 32 patients. A preliminary analysis of the results of these early operations showed that the best results came from lesions in the postero-medial part of the pallidum. In later operations the range of variation was much smaller within this effective zone. . . 81 patients with Parkinsonism, aged 30-75, were operated upon at the department of neurosurgery in Lund (Sweden) 1953-57 with Leksell's stereotactic technique. Thermolesions in the postero-medial part of the pallidum were produced by a high frequency alternating current applied to a pair of electrodes under control of the tissue temperature. In the first $2 / 3$ of this series the site of the lesion and the tissue temperature were systematically varied. In the last 20 consecutive cases operated on unilaterally a standardized lesion was produced. The time of postoperative follow-up was 1-5 years [131].

Note the work of the Swedish group was long before Bergman's paper on MPTP-monkeys. The role the GP played in movement disorders was well known, as was the fact that the STN played a role. The fact that the GP was operated on long before Bergman's studies proves that the supposed benefit from the MPTP-monkey studies was not considered necessary by the medical community prior to operating on structures known from human studies to be involved in movement disorders.

Another reason the MPTP monkey model receives undue credit for DBS is in part a causality of the success of modern medicine. After L-dopa was discovered and administered to patients with PD in the 1960s, the need for surgery was dramatically decreased. Even if the value of the STN and GP had been unknown in the 1990s, neurosurgeons could have discovered it simply by stimulating these areas, as microelectrodes were available by the 1960s [165-167]. That is the way much of the research on movement disorders proceeded. Human-based trial and error is still acceptable provided the risk of harm is minimal. Hutchison et al. stated in 1994:

Microelectrode trajectories through the globus pallidus of 6 Parkinson's disease (PD) patients yielded neurophysiological, landmarks which enabled the identification of neurones located in the external segment (GPe) and internal segments, exterior $(\mathrm{GPi}, \mathrm{e})$ and interior $(\mathrm{GPi}, \mathrm{i})$ of globus pallidus and the surrounding borders (Bor). Firing rate histograms and inter-spike interval time histograms were constructed for neurones in each region. The neuronal activity in GPi,i was higher than in the other segments, and a high degree of bursting was found in GPe and GPi neurones.
This profile of neuronal activity is similar to that observed in monkeys treated with MPTP, suggesting that the observed level of activity of neurones in $\mathrm{GPi}, \mathrm{i}$ is excessive, and contributes to the bradykinesia and rigidity of PD patients [168]

Sterio et al. stated in 1994:

Neuronal properties of the human globus pallidus (GP) are not known. Since GP is the major output of the basal ganglia, it may be involved in the pathophysiology of Parkinson's disease. We studied 12 patients with medically resistant Parkinson's disease by using single cell recording of the GP during stereotaxic pallidotomy to define neuronal firing rate and its modulation during active and passive movements [169].

Lozano et al. also described human studies in 1996:

Methods for localizing the posteroventral globus pallidus internus are described. The authors' techniques include the use of microelectrodes to record single-unit activity and to microstimulate in human pallidum and its surrounding structures. This technique allows a precise determination of the locations of characteristic cell types in sequential trajectories through the external and internal segments of the pallidum. The location of the optic tract can be determined from microstimulation-evoked visual sensations and recordings of flash-evoked potentials. In addition, microstimulation-evoked motor and sensory responses allow the internal capsule to be identified. The data collected using this technique are an important adjunct to selecting optimum sites to place electrocoagulation lesions for stereotactic posteroventral pallidotomy for refractory Parkinson's disease [170].

The above forces one to question the value of the monkey studies if such data can be so easily obtained from humans. Moreover, the same outcomes may be caused by very different mechanisms, as we will see. Therefore, what is demonstrated in the monkey studies cannot be extrapolated to human without critical examination. Recently, Follett et al. revealed that DBS at either the STN or the GPi resulted in similar relief from the motor symptoms of PD including tremor and stiffness [171].

As the history of surgery on the thalamus is not usually attributed to animal studies we will only briefly examine it here. Lesioning the thalamus in order to treat MD dates back to well prior to the $1980 \mathrm{~s}$ [172-181]. Procedures on the thalamus were performed in the 1960 s by Andy, who used radiofrequency DBS to confirm the exact site for the lesion. Andy et al. 1963:

In the neurosurgical treatment of parkinsonian tremor, a major question to be answered is, where is the optimal site of target for the lesion? The present study is an attempt to evaluate the posterior ventrolateral area of the thalamus, internal capsule, medial region of the globus pallidus and posterior subthalamus. With reference to the various atlases available, it appeared that the optimum site for the most efficient lesions corresponds to the posterior subthalamus which includes the field $\mathrm{H}$ of Forel, the zona incerta, and the prerubral field medial to the subthalamic nuclei [182].

Andy and others went on the perform thalamic surgery for movement disorders for decades [183]. Hassler et al. compared clinical data with autopsy findings and concluded that lesioning the nucleus ventro-oralis anterior (VOa) and the nucleus ventro-oralis posterior (VOp) had a limited affect on rigidity [184]. They also concluded that lesioning the nucleus ventralis intermedius (Vim), was the best treatment for tremor $[159,185-187]$. These results were replicated by others $[181,187,188]$. 
Also of note is the fact that Hassler et al. thought they were operating on the thalamus at times but turned out to have lesioned the STN [184] linking once again the STN to MDs. The Vim was known to be involved in MDs and DBS on the Vim had been performed for MDs prior to 1987. Benabid et al. even stated in 1987: "Stereotactic thalamotomy of the thalamic nucleus centralis intermedius (VIM) is routinely used for movement disorders. During this procedure, it has been observed that high-frequency $(100 \mathrm{~Hz})$ stimulation of VIM was able to stop the extrapyramidal tremor" [189].

\section{Claim 3}

The claim that the concept of lesioning, or disrupting with electrical stimulation, the STN and the GPi in order to alleviate motor disturbances, as well as the frequency at which to use DBS arose secondary to MPTP experiments on monkeys.

The use of electricity or electrical discharge has been used for millennia in the treatment of numerous disorders. Romans used the torpedo fish or electric ray (Torpedo torpedo) as a treatment for headaches. They continued to be used for various conditions into the 1800s [190-192]. In the 1780s, Galvani famously connected the nerves of a dead frog to a lightning rod and observed the legs twitch. Prior to 1804, Aldini studied cadavers, fresh from the guillotine, and used electrical stimulation on the surface of the cortex. The resulting grimaces convinced him and others that such stimulation might be therapeutic $[193,194]$. Because Aldini suggested a therapeutic application, he could be considered the father of DBS. In 1809, Rolando used electrical stimulation on the cortex of animals [195]. (We note that although humans were apparently the first to be studied regarding a number of neuroanatomies during this time, we do not think this is relevant to the discussion of the role of animals in the development of DBS. There are numerous demonstrations or studies that were performed on humans or animals first and subsequently on the other. Either could have been studied first and indeed the one that history records as being first may not have been. The historical records were not detailed and no doubt much has been lost. Regardless, we wish to point out that irrespective of which species went first, humans or animals would have yielded the needed information, hence instances like these do not support an argument that animals were necessary or that humans were necessary for the advance. Either would have sufficed, provide the animal-based result was replicated in humans).

Throughout the 1800s, animals and humans were studied [196] and the link between electrical stimulation of the brain and actions and developed. Horsley would be the next to advance the study of stimulation. Horsley's sense for precision, in addition to leading to the development of the stereotactic device, also led to the development of small electrodes that could carry a current thus ablating a very small and very specific area of the brain [61]. Another example of advances secondary to engineering. Horsley and Clarke however, were apparently not the first to use electrodes per se. The Russian Golsinger used electrodes to lesion the brains of dogs in 1895 [20,61]. Cooper went on to implant electrodes for numerous conditions and pioneered surgery in the field. In 1979, Cooper implanted electrodes for DBS and tried various frequencies in a number of procedures including DBS of the thalamus and electrical stimulation of the cerebellum $[46,197,198]$. Beginning in the 1960s, electrostimulation was used for confirming the needle placement for thalamic lesions [63,165-167].

Gabriel and Nashold state:
The efficacy of the capsular lesion was thought to be related to the interruption of the ansa and fasciculus lenticularis and their connections with the reticular substance, subthalamic nucleus, and substantia nigra. . . . In 1963, Andy et al. used a radiofrequency current to evaluate the optimal lesion site in 58 patients with parkinsonian tremor. By correlating their data with stereotactic atlases, they concluded that the most efficient lesion site was in the posterior subthalamus and included Field $\mathrm{H}$ of Forel, zona incerta, and the prerubral field medial to the subthalamic nuclei [86].

A publication by Medtronic even states: "Deep brain stimulation (DBS) emerged in the late 1960s as a possible therapeutic alternative to lesioning in patients with severe, chronic, intractable pain" [1].

Medtronic's website acknowledges the long history of using DBS to isolate areas in the brain:

Neurologists and neurosurgeons have used electrical stimulation since the 1960 s as a way to locate and distinguish specific sites in the brain. During the process, they discovered that stimulation of certain brain structures suppresses the symptoms of neurological disorders such as Parkinson's disease, essential tremor, and dystonia [199].

The development of the stimulator unit and battery is due to advances in engineering and computer science.

Natalia Petrovna Bekthereva first applied DBS chronically in 1963. Because she published in Russian, her works were not well known until 1975 [200-202]. McLellan soon followed in the 1970s [196,201,203] but some had so employed DBS dating back to the 1960s [181,185,204206]. Starting in 1975, Mundinger used deep brain stimulation of the ventrolateral thalamus for the treatment of movement disorders and reported successfully treated cases in 1982 [207]. Mundinger, in 1977, treated torticollis by implanting a stimulator in "the extrapyramidalmotor thalamic nuclei (V. o. a. /V. o. i. ) and the subthalamic zona incerta including the pyramidal tracts $\mathrm{H} 1$ and $\mathrm{H} 2$ (according to Forel) " [208]. Cooper reported on a series of patients treated with DBS in 1982 [209]. Brice and McClellan implanted deep brain stimulators to target the region of the subthalamus, thereby controlling the tremor of patients with multiple sclerosis in 1980 [210]

The fact that frequency influenced activity was also appreciated by the end of the 1950s $[53,57,165,196,211-217]$. Electrical stimulation was used, for among other things, to isolate the exact area to lesion. Hassler [204], noted in 1960 that by increasing the frequency the abnormal movement could be suppressed or increased [218].

Radiofrequency stimulation of the thalamus and BG was also demonstrated to inhibit motor activity in monkeys $[69,189]$. This is the basis for the claim that monkeys were vital for the implementation of DBS in MDs, especially for PD. Benabid et al. [189] reported in 1987 that the frequency of stimulation that best abolished tremor was $100 \mathrm{~Hz}$ or greater. In 1995, they reported their results of using DBS on the STN in patients with PD and other MDs [69]. Benabid, et al. [219] stated:

Animal experiments in MPTP monkeys have demonstrated that dopaminergic deafferentation induces a hyperactivity in the subthalamic nucleus (STN) [147]. Distinction of STN suppresses rigidity and akinesia [64] in these animals. Subthalamotomy in human patients cannot be considered, due to the high risk of inducing hemiballism. We assumed that high frequency stimulation could inhibit STN as it inhibits the Vim nucleus for tremor [220]. This hypothesis was validated by animal experiments 
which demonstrated that high frequency stimulation of STN in MPTP monkeys acutely reversed rigidity and akinesia [221]. This allowed us to perform this procedure in human patients, in whom we also observed the alleviation of akinesia and rigidity in the operating room [222].

The above clearly states that use of DBS in the STN was secondary to experiments on monkeys. Gross and Lozano echo this:

Based on the work of DeLong et al. and Alexander and Crutcher establishing the central role of the STN in the pathophysiology of PD in animal models, Benabid et al. pioneered the application of deep brain stimulation within STN. . . to the treatment of Parkinson's patients. They demonstrated remarkable clinical effects and tolerability of bilateral STN DBS on all parkinsonian features including gait disturbance [223].

Brice and McClellan implanted deep brain stimulators to target the region of the $\mathrm{BG}$, thereby controlling the tremor of patients with multiple sclerosis in 1980 [210]. They reported that frequencies of $75-150 \mathrm{~Hz}$ were optimal for abolishing tremor. Around the same time, Cooper et al. used deep brain stimulation of the ventrolateral thalamus and reported encouraging results in patients with cerebral palsy [209]. Siegfried went on to demonstrate the successful use of deep brain stimulation in the thalamus of patients with chronic pain and dyskinesia [224,225]. All of this was prior to the 1983 study of MPTP monkeys [7].

Also contrary to the statements by Gross and Lozano and Benabid, the groundwork for using DBS on the STN actually came from human studies. Cooper [46] had performed DBS in humans for movement disorders eleven years earlier and, as we have shown, when Bergman et al. operated on the STN, it was already known from human studies to be involved in MDs. The MTPT monkey studies appear to have renewed interest in the STN as an area of interest in movement disorders and it appears that Benabid et al. did proceed to operate on the STN sooner than they otherwise would have. This in and of itself is unfortunate because studies in animal models were apparently considered more important than decades of studies in human anatomy and neurosurgery on humans. If Benabid and others were unaware of these studies, that is also suboptimal as any decent literature search would have informed them of these facts prior to, and obviating the need for, studies in animals. Examples like this have implications for Institutional Animal Care and Use Committees.

This use of deep brain stimulation therefore predates the very first description of the MPTP monkey model of Parkinson's disease by nearly 40 years. A fully implantable and reversible stimulator system for movement disorders was developed circa 1980, three years before the Parkinson's disease MPTP monkey model was even first described.

The ability of electricity to alter MDs was well known prior to the early 1980s and the MPTP experiments with monkeys. In the late 1970 s, surgeons were able to permanently implant electrodes, in part, because of the advances in battery technology inspired by the cardiac pacemaker. The development of DBS would not have been possible without advances in engineering and computer science.

\section{Epistemology and mechanisms}

When asking questions akin to, "what modalities were necessary for $\mathrm{X}$ to have been discovered," one is in the realm of epistemology and philosophy of science. Giere, Bickle, and Mauldin explain: the burden of proof is on the producers, or purveyors, of that information. They have to convince you that they are right. That means they have to provide you with data that constitute good evidence for their claims. You, like a jury, need only evaluate what they provide. Thus, if you conclude that the data supplied do not provide good evidence for their claims, you have done your job. You have reached the useful conclusion that you need not, at least for the moment, pay any more attention to their claims [226].

We conclude that scientists that claim animal models were necessary for the development of DBS have the burden of proof on them and that they have not met this challenge. We note that failing to meet this standard does not conclusively prove that animal models were unnecessary, merely that the proofs are inadequate. We further note that even though the burden of proof was not on us to falsify the position that animal models were necessary for the development of DBS, we have presented a strong case for just that position.

There is no question that animal models were used in the development of DBS but they appear to have been neither necessary nor sufficient. The reason they were not sufficient lies in the fact that animals and humans are examples of living evolved complex systems, which makes inter-system extrapolation problematic. The problems associated with extrapolating results from one living, adaptive, complex system to another have been addressed many times $[22,24,26-$ $36,77,227-231]$ so we will not reproduce them here. Conversely, there is no doubt that animal models can function well as heuristics $[35,232$ $234]$ as well as in many other endeavors $[33,35]$. However, the success of animal models in these endeavors does not fulfill the burden of proof for the claim of being a predictive modality in general or for the claim of necessity for the development of DBS. The fact that many drug and disease outcomes in humans have been shown to exist in some animal model is also immaterial as retrospectively picking an animal model that reproduces human data is not helpful either in terms of mechanisms or for predicting future human responses. This leads us to the mechanisms issue.

The fact that inter-species variation occurs in anatomy should inform us regarding mechanisms. For example, Alam et al. discuss the differences among species in the anatomy of the area of pedunculopontine nucleus, which has been targeted for deep brain stimulation in patients with MDs [235]. DeFelipe et al. discuss human monkey differences in double-bouquet cells (DBC) stating:

We will see that there are important differences in the morphology, number and distribution of DBC horsetails between areas 17 and 18 in the primate. This suggests important differences in the microcolumnar organization between these areas, the functional significance of which awaits detailed correlative physiological and microanatomical studies [236].

Benabid clearly attributes the advancement of DBS, including mechanisms, to animal-based studies [237,238]. Despite all the importance placed on mechanisms, the mechanisms by which DBS affects the signs of MDs are still unknown despite decades of research using animals [239-241]. This is an important element in our analysis of animal models and DBS as one of the reasons animal models in general have been heralded as important, indeed vital, is for the search for mechanisms. If they have failed in this respect, and the historical aspects of DBS development imply that animal models were not necessary, then one must question the use of animal models specifically for the development of DBS and perhaps in certain aspects of research in general [32-36,77]. Moreover, the search for mechanisms 
has been the defining modus operandi of basic research in general and animal-based research in particular. However, some in the scientific community $[242,243]$ and even in the basic research community are now pointing out the poor track record of this enterprise. Marincola, editor of the Journal of Translational Medicine, discussed the reliance on a search for mechanisms and a hypothesis driven approach to research as opposed to observations of natural processes. He questioned the premises on which some of these hypotheses are based and argued for more observation-based studies. Marincola:

It is surprising how often a manuscript is dismissed by reviewers as "just descriptive", regardless of the novelty of the reported observation. On the other hand, we have not once received a negative comment on a "mechanistic" study, even if it lacks proof of the validity of the experimental model and its relevance to human disease [244].

Marincola goes on to ask if anyone would worry about the mechanism for a drug that cures $100 \%$ of human cancer if it were discovered through serendipity. The focus on mechanisms has impeded science many times. For example, Wegener's continental drift hypothesis was rejected because of lack of mechanism $[245,246]$. Darwin also lacked a mechanism when he published Origins.

Johnston discusses the failure of basic research to improve human health to the degree that it should have. He uses as examples of this failure the fact that despite a doubling on the NIH budget the number of new chemical entities entering the market remains steady and the fact that despite fascinating research into the mechanism of stroke, essentially no drugs for neuroprotection have entered the market as a result of this largely animal-based research. Johnston:

Introspection into the science of science is rare. Thirty years after its publication, for example, an analysis of research contributing to major medical advances remains a frequent citation in support of funding for basic science even though it is now 30 years old and has been widely criticized. There are many questions that could be answered with careful objective analysis. Is current allocation of resources to translational research appropriate? Is peer review working? Are research funds distributed reasonably and equitably across diseases? Has society seen a return on the research investment? These are the sorts of questions that should be addressed as rigorously and as scientifically as possible [247].

Furthermore, the mechanisms for diseases that appear at first glance to be identical among species have been discovered to be very different. Jacks notes that: “. . . the genetic wiring for growth control [cancer growth] in mice and humans is subtly different" [248]. Anisimov, Ukraintseva, and Yashin state that while there are similarities between rodents and humans regarding the genes involved in carcinogenesis, the differences tend to override them. For example, they cite Weinberg et al. $[249,250]$ who discovered that fewer genes and pathways are required to induce cancer in mice than humans [251]. Rangarajan and Weinberg 2003 state: "These observations indicated that mouse and human cells indeed have quite distinct requirements for cellular transformation" [250]. Chabner and Roberts also cite Weinberg et al. and state: "Attempts to produce genetically engineered mouse models of human cancer in fact lead to models of the specific molecular changes in a mouse cell, and have uncertain relevance to a human counterpart" [252]. Gupta and Sen point out that animal models of heart failure have been mechanistically unrewarding [253]. These examples could easily be multiplied [254-256].
Furthermore, there are more reasons to distrust the mechanisms approach. For example, there are reasons based in evolution to explain the fact that different mechanisms can produce similar traits or effects [35]. Kirschner and Gerhart discuss conserved processes and facilitated variation and contrast the eye of the octopus with the eye of human. Both eyes appear similar and result in vision but they evolved using very different mechanisms. Kirschner and Gerhart note that the circuitry of the two eyes are very different and:

the phototransduction circuits are completely different (involving components that are different but common to both organisms) is a testimonial to the power of conserved processes-they can be organized by different means to a similar end. In convergence, similar outcomes are evolved in different ways, making use of exploratory processes, modularity, flexibility, and weak linkage. Anatomical convergence at the level of these processes is no different than anatomical diversification [[257] p240-1].

Moreover, when one wishes to discuss past discoveries made in one species that turned out to be similar to the anatomy or pathophysiology in another, one must also keep in mind the fact that important differences also exist even in these instances. For example, the anatomy of the human and macaque brains is known to differ in important areas [258,259]. The occasional observations or discoveries of correlations do not fulfill the requirements for a practice to be considered predictive in medical science $[35,36]$. Such observations can be useful heuristics, however [234].

Surgical procedures and anatomy are not an exception to the above. Staying with the subject of neurosurgery, intracranial-extracranial bypass was shown to be very effective in animal models [260,261] but increases morbidity in humans [262-265]. Radial keratotomy (RK) of the mid $20^{\text {th }}$ century was practiced in rabbits, which experienced no problems, however many humans experienced corneal edema and vision loss because of differences between the corneal endothelium of rabbits and humans. The reason that humans, as opposed to rabbits, eventually experienced blindness was secondary to the fact that humans could not recover from one of the incisions placed posteriorly in the cornea [266-272]. Current operations to correct myopia have little in common with the original RK.

All of the above must be placed into the context of where past breakthroughs have come from. Weinberger states: "All psychiatric drugs in common use today are derivatives of treatments that were originally discovered by accident. None were developed based on a scientific understanding of the causes or pathophysiology of mental illness" [273]. Yang and Sonner state: "Inhaled anesthetics have historically been discovered either serendipitously [274], or through an empirical process of trial and error" [275]. The mechanisms of general anesthesia continue to elude scientists, although it is currently a focus of research [276-279]. The original treatment for ventricular dysrhythmias was discovered accidentally when a cardiologist noticed that lidocaine decreased their occurrence. Lasagna states that lidocaine was one of many medications the effects of which: "were not discovered except by serendipity after their clinical introduction for other purposes" [280]. The idea of treating hypertension with diuretics was also serendipitous [281]. In 1937, physicians noticed that when patients were given medications that increased urine output, they began to breathe better. The ultimate result was the thiazide diuretics. These examples could be easily multiplied.

We are not suggesting reliance on serendipity, however. Rothwell stated in 2006: 
Indeed, most major therapeutic developments over the past few decades have been due to simple clinical innovation coupled with advances in physics and engineering rather than to laboratory-based medical research. The clinical benefits of advances in surgery, for example, such as joint replacement, cataract removal, endoscopic treatment of gastrointestinal or urological disease, endovascular interventions (eg, coronary and peripheral angioplasty/stenting or coiling of cerebral aneurysms), minimally invasive surgery, and stereotactic neurosurgery, to name but a few, have been incalculable. Yet only a fraction of non-industry research funding has been targeted at such clinical innovation. How much more might otherwise have been achieved [282]?

\section{Discussion}

Why is this topic important? One reason is simple historical accuracy. Renditions of past medical advances should be accurate. Another reason is that the geneses of past advances are used to inform future decisions. There are both funding and ethical implications to be derived from an accurate rendition of history. This must be placed in the social context of the reality that the use of animals in research is controversial from many respects. The recent US Institute of Medicine Report on the use of chimpanzees in research is but one example of society struggling to come to grasps with the situation [283]. Furthermore, recent work has called into question the use of animal models to predict human response to drugs and disease [33-36,227,242,284]. This is a key aspect of animal-based research as Giles, writing in Nature confirms:

In the contentious world of animal research, one question surfaces time and again: how useful are animal experiments as a way to prepare for trials of medical treatments in humans? The issue is crucial, as public opinion is behind animal research only if it helps develop better drugs. Consequently, scientists defending animal experiments insist they are essential for safe clinical trials, whereas animal-rights activists vehemently maintain that they are useless [285].

The claim that animal models can be predictive modalities for human response to disease and drugs has been refuted [32-36,77,227,286-304]. The role of animal models in the development of DBS, as explained by the animal model community, clearly claim that such models were predictive for humans. This claim has been empirically shown to be false as most of the predictions were in fact retrospectively produced findings that reproduced human data and even here different animal models yielded different results. One cannot cherry pick the animal model data in order to find the model that correlated with humans and thus claim predictive ability for the model. A model must be judged on the basis of the history of numerous predictions so the positive predictive value (PPV) and negative predictive value (NPV) can be calculated and the model's predictive ability thus assessed. (For more on what makes a model predictive see references [32,33,77,305-307]. ) The ability of a modality, be it a diagnostic test, intervention, or practice to be classified as predictive should not be confused with the routine generation of prediction by hypotheses that allow the hypotheses to be strengthened or falsified, although this fallacy is frequently committed [36,227,308-314].

The possibility that animal models can be predictive modalities for human response to drugs and disease has also been shown to be false based on Theory $[32,35,77,315,316]$. To be clear, theory is not synonymous with hypothesis. The National Academy of Sciences (USA), explains theory as follows:

In everyday usage, "theory” often refers to a hunch or a speculation.
When people say, "I have a theory about why that happened," they are often drawing a conclusion based on fragmentary or inconclusive evidence. The formal scientific definition of theory is quite different from the everyday meaning of the word. It refers to a comprehensive explanation of some aspect of nature that is supported by a vast body of evidence. Many scientific theories are so well established that no new evidence is likely to alter them substantially. One of the most useful properties of scientific theories is that they can be used to make predictions about natural events or phenomena that have not yet been observed [[317] p11].

Knowledge regarding the material universe gained from complexity science and evolutionary biology have given us a Theory that explain the empirical evidence that shows animal models are not predictive. Stated briefly: animals and human are evolved complex systems and therefore very small differences between species and even between individuals of the same species will lead to very different outcomes to perturbations to the system $[31,35,316]$. There is much support in the scientific literature for this position. For example, Sharp and Langer state: "The next challenge for biomedical research will be to solve problems of highly complex and integrated biological systems within the human body. Predictive models of these systems in either normal or disease states are beyond the capability of current knowledge and technology" [299].

Weinberg was quoted by Leaf in Fortune magazine as saying: “And it's been well known for more than a decade, maybe two decades, that many of these preclinical human cancer models have very little predictive power in terms of how actual human beings-actual human tumors inside patients-will respond preclinical models of human cancer, in large part, stink. . . hundreds of millions of dollars are being wasted every year by drug companies using these [animal] models" [318]. Ellis and Fidler: "Preclinical models, unfortunately, seldom reflect the disease state within humans" [243]. Oliff, formerly of Merck stated: "The fundamental problem in drug discovery for cancer is that the model systems are not predictive at all" [248]. In 2006, then US

\begin{tabular}{|l|l|l|l|}
\hline Subject & Fiscal Year & $\begin{array}{l}\text { Extramural } \\
\text { ResearchDollars,\% }\end{array}$ & $\begin{array}{l}\text { Total Projects } \\
\text { And SubProjects, \% }\end{array}$ \\
\hline Humans & 1977 & 27.5 & 32.4 \\
& 1978 & 26.8 & 31.2 \\
& 1979 & 26.8 & 29.2 \\
& 1980 & 25.0 & 28.9 \\
& 1981 & 23.8 & 29.7 \\
& 1982 & 23.2 & 31.5 \\
& 1983 & 22.9 & 32.2 \\
\hline Mammals & 1977 & 43.5 & 41.9 \\
& 1978 & 44.0 & 42.5 \\
& 1979 & 44.9 & 43.8 \\
& 1980 & 45.0 & 44.2 \\
& 1981 & 47.3 & 44.1 \\
& 1982 & 48.1 & 43.5 \\
& 1983 & 47.9 & 42.7 \\
\hline Other & 1977 & 29.4 & 25.6 \\
& 1978 & 29.3 & 26.3 \\
& 1979 & 28.2 & 27.0 \\
& 1980 & 29.8 & 26.9 \\
& 1981 & 28.9 & 26.0 \\
& 1982 & 28.7 & 25.0 \\
& 1983 & 29.2 & 25.1 \\
\hline
\end{tabular}

anpublished information provided by Division of Research Resources, Nationa Institutes of Health

'This category includes invertebrates, nonmammalian vertebrates, bacteria, viruses, mathematical and computer simulations, and other subjects

Table 1: Distribution of NIH Support of Extramural Research among Humans Laboratory Mammals, and Other Research Subjects, Expressed as Percentages of Total Dollars and of Total Projects and Subprojects. ${ }^{\text {a }}$ 
Secretary of Health and Human Services Leavitt stated: "Currently, nine out of ten experimental drugs fail in clinical studies because we cannot accurately predict how they will behave in people based on laboratory and animal studies" [290]. Examples of such statements could easily be multiplied.

Giles' statement must be placed into the context of basic research. The actual role of animal models in the development of DBS was in the realm of basic research and recent work has also forced a re-evaluation for the historical role of such use of animal models $[32,34,35,227,315,319-321]$. Both the prediction issue and the actual historical development of an advancement or discovery are important factors that should be considered when society is evaluating the role of animal models in the future.

This raises the question of funding and ethics. US funding agencies such as the NIH have been criticized for disproportionately funding basic research [322-325]. Well-publicized breakthroughs in basic research have not lead to advances in the stated goal of NIH, which is "to reduce the burdens of illness and disability [326]." Approximately $70 \%$ of NIH's research budget goes to basic science $[323,325]$. The percentage in the UK is about the same [327-331]. The last published data on NIH funding was published in a 1985 publication from the Committee on Models for Biomedical Research, Board on Basic Biology (Table 1) [332]. According to the Committee, greater than or equal to $50 \%$ of NIH extramural research dollars was awarded to research involving sentient animals. At least $45 \%$ was awarded to research on mammals (most people consider mammals sentient and many even consider all vertebrates sentient [333-344]). An additional 30\% was awarded to research involving nonmammalian vertebrates and so forth. (Based on the previous references, many people think at least some of these animals are sentient). Assuming some of the nonmammalian vertebrates are sentient, then the total funding awarded is easily over $50 \%$. Based on these numbers and NIH's predisposition to fund basic research, it appears feasible that at least $50 \%$ of extramural funding was historically awarded to basic research on sentient animals and there is no evidence that this has changed.

The percentage of research grants awarded for research using sentient animals is relevant as society clearly has reservations regarding such research. Per Giles, the return for such practices needs to be direct and important. Giles comment is supported by polls and surveys. An editorial in Nature in 2009 reinforced the above stating: "Animalresearch policies need to be guided by a moral compass-a consensus of what people find acceptable and unacceptable" [345]. What does society find acceptable?

A survey conducted by YouGov in the UK, France, Germany, Italy, Sweden and the Czech Republic asked under what conditions should the use of dogs, cats, and primates in research be allowed.

- $81 \%$ of people surveyed agree or strongly agree the new law should prohibit all experiments causing pain or suffering to primates.

- $79 \%$ of people agree or strongly agree the new law should prohibit all experiments on animals which do not relate to serious or life-threatening human conditions.

- $84 \%$ of people surveyed agree or strongly agree the new law should prohibit all experiments causing severe pain or suffering to any animal.

- $73 \%$ of people disagree or strongly disagree that the new law should permit experiments causing pain or suffering to cats.
- $77 \%$ of people disagree or strongly disagree that the new law should permit experiments causing pain or suffering to dogs [346].

The Pew Research Center and the American Association for the Advancement of Science (AAAS) revealed, in 2009, that only 52\% of nonscientists supported the use of animals in general in scientific research [347]. In 1999, MORI and New Scientist [348] asked people whether they favored using animals with $24 \%$ answering yes $64 \%$ answering no. The questions were then divided into several categories. Respondents were questioned about experiments in which mice would be subject to pain, illness or surgery, and $61 \%$ stated that they disapproved using mice in order to study how the sense of hearing works. That percentage dropped to $32 \%$ when the question concerned the use of mice to ensure a new drug to cure childhood leukemia was safe and effective. When monkeys were substituted for mice the disapproval went from $64 \%$ to $75 \%$ and $32 \%$ to $44 \%$, respectively. As the previous sections reveal, animals cannot in fact be used to predict safety and efficacy and are in reality used for basic research, which The Organization for Economic Cooperation and Development defined as: "Experimental or theoretical work undertaken primarily to acquire new knowledge of phenomena and observable facts without any particular application or use in view. It is usually undertaken by scientists who may set their own agenda and to a large extent organise their own work" [349].

While the above polls reveal variation in response the general message is clearly that society is uncomfortable with using animals in basic research. Since animal models are not predictive for human response to drugs and disease, including cancer, it would appear that, if society understood this, it would not approve of using animals in such a fashion [227].

Finally all of the above must be contrasted with the statements of those whose function is to promote the use of animals in research. For example, Understanding Animal Research, a UK-based nongovernmental organization that promotes animal-based research, states on their website:

Monkey research identified a potential target for DBS: a structure in the brain known as the subthalamic nucleus (STN). Continuous stimulation delivered by a wire inserted into the STN, and driven by a battery stimulator implanted under the collarbone, blocks the abnormal nerve signals that cause tremor and other Parkinson's symptoms [350].

Such examples regarding the development of DBS are easily multiplied [8-14,16,351-356].

An oft-overlooked area of ethical concern is the fact that the research pie is finite and funding awarded to animal-based research is not available to more productive areas [282,357-362]. In light of the competing financial interest for research funding and the ethical concerns of society, a clear presentation of historical developments is important.

\section{Summary}

The fact that the true history of any discovery, be it one from the distant past or more recently, is difficult to unravel is, at least in part, what led Medawar [363] to write his famous essay, "Is the scientific paper a fraud?" The relevant concepts involving the basal ganglia and movement disorders were known in the early 1900s. Clearly, lesioning the central nervous system was already a well-known treatment for 
movement disorders in the early $20^{\text {th }}$ century. The knowledge of where to lesion for what effect was learned from studying humans including humans who suffered various traumas. Autopsies and the observation of, and research on, living humans were used in this endeavor, as was what today might be called human experimentation. As soon as DBS was introduced it could justifiably and ethically have been applied to any structure in the basal ganglia in hope of alleviating movement disorders. Such trial and error continues even now.

Human observation, autopsies, surgical trial and error, advances in engineering and computer science, as well as serendipity figured greatly in the development of DBS. Animals were used in the early days of neuroanatomy and neurosurgery research but the knowledge gained appears to either have replicated human studies or could have been ascertained from human studies (anatomy), or may have been obtainable without animals because of the nature of the discovery (the stereotactic device from engineering). Regardless, the knowledge that could, arguably, only have been obtained from animal studies appears to have been in the very early days of modern neuroanatomy research. This does not demean the value of animal models but it does place them into a different context than the claim that they were necessary. It also refutes common claims such as that the STN was only known to be involved in specific MDs secondary to the MPTP monkey studies.

Hindsight is also aided by current knowledge of evolutionary biology, complexity science, and empirical evidence in essentially all areas of animal modeling. Both theory and empirical evidence demand skepticism when evaluating past claims that animal models predicted human response to perturbations to the system as a whole or that animal models were necessary for such discoveries. This does not imply that animal models were unimportant for discovering myriad facts regarding living systems in general. Nevertheless comparative research and the discovery of fundamentals of life are not what are claimed concerning the role of animal models in the development of DBS.

The role of animal models in the development of DBS is but one facet that must be considered when analyzing the use of animals in science. Nevertheless, any evaluation of animal models, be it for the development of DBS or the predictive value of monkeys for drug response, should be science-based and honest. In the case of DBS, as is true for all claims regarding animal models, a proper understanding of the advance has financial implications in terms of which projects are funded and thereby ethical implications for both animals and human patients.

\section{Acknowledgements}

We thank Marius Maxwell MBBChir, DPhil, American Board of Neurological Surgery, for use of previous writings on this subject (see http://www. vero. org. uk/ press15. asp).

\section{Authors' Information}

Ray Greek, MD is board certified in anesthesiology, has been on staff at the University of Wisconsin and Thomas Jefferson University, and is the president and co-founder of the not-for-profit Americans For Medical Advancement (www. AFMAcuredisease. org).

Lawrence A. Hansen, MD is Professor of Neuroscience and Pathology, Department of Neurosciences at the University of California, San Diego.

\section{References}

1. Sarem-Aslani A, Mullett K (2011) Industrial perspective on deep brain stimulation: history, current state, and future developments. Front Integr Neurosci 5: 46.

2. Davis GC, Williams AC, Markey SP, Ebert MH, Caine ED, et al. (1979) Chronic Parkinsonism secondary to intravenous injection of meperidine analogues. Psychiatry Res 1: 249-254.
3. Gibb BJ (2007) The Rough Guide to the Brain. Rough Guides Ltd, London.

4. Fahn S (1996) Book Review: The Case of the Frozen Addicts: How the solution of an extraordinary medical mystery spawned a revolution in the understanding and treatment of Parkinson's disease. N Engl J Med 335: 2002-2003.

5. Langston JW, Palfreman J (1995) The Case of the Frozen Addicts. Vintage Books, California, USA

6. Langston JW, Langston EB, Irwin I (1984) MPTP-induced parkinsonism in human and non-human primates--clinical and experimental aspects. Acta Neurol Scand Suppl 100: 49-54.

7. Burns RS, Chiueh CC, Markey SP, Ebert MH, Jacobowitz DM, et al. (1983) A primate model of parkinsonism: selective destruction of dopaminergic neurons in the pars compacta of the substantia nigra by N-methyl-4-phenyl-1,2,3,6tetrahydropyridine. Proc Natl Acad Sci USA 80: 4546-4550.

8. Pereira EA, Aziz TZ (2006) Parkinson's disease and primate research: past, present, and future. Postgrad Med J 82: 293-299.

9. Pereira EA, Aziz TZ (2006) Surgical insights into Parkinson's disease. Journal of the Royal Society of Medicine 99: 238-244.

10. Grover PJ, Pereira EA, Green AL, Brittain JS, Owen SL, et al. (2009) Deep brain stimulation for cluster headache. J Clin Neurosci 16: 861-866.

11. Pro-Test (2006) Parkinson's Disease. Pro-Test.

12. Kringelbach ML, Jenkinson N, Owen SL, Aziz TZ (2007) Translational principles of deep brain stimulation. Nat Rev Neurosci 8: 623-635.

13. Baunez C (2011) A few examples of the contribution of animal research in rodents for clinical application of deep brain stimulation. Prog Brain Res 194 105-116.

14. Sorensen JC, Nielsen MS, Rosendal F, Deding D, Ettrup KS, et al. (2011) Development of neuromodulation treatments in a large animal model--do neurosurgeons dream of electric pigs? Prog Brain Res 194: 97-103.

15. Blomstedt P, Hariz MI (2010) Deep brain stimulation for movement disorders before DBS for movement disorders. Parkinsonism Relat Disord 16: 429-433.

16. Wishart A (2006) What Felix the monkey taught me about animal research London Evening Standard, February 16.

17. Ringach D (2012) A Brief History of Deep Brain Stimulation. Speaking of research, August 9.

18. Katz J (1969) The education of the physician-investigator. Daedalus 98: 480 501

19. Altman L (1998) Who Goes First? The Story of Self-Experimentation in Medicine. University of California Press, California, London.

20. Marshall LH, Magoun HW (1990) The Horsley-Clarke Stereotaxic Instrument The Beginning. David Kopf Instruments, October 22.

21. Van Hooser SD (2007) Similarity and diversity in visual cortex: is there a unifying theory of cortical computation? Neuroscientist 13: 639-656.

22. Ahn AC, Tewari M, Poon CS, Phillips RS (2006) The limits of reductionism in medicine: could systems biology offer an alternative? PLoS Med 3: e208.

23. Goodwin B (2001) How the Leopard Changed Its Spots : The Evolution of Complexity. Princeton University Press, New Jersey, USA.

24. Kitano H (2002) Systems biology: a brief overview. Science 295: 1662-1664.

25. Novikoff $A B(1945)$ the concept of integrative levels and biology. Science 101: 209-215.

26. Ottino JM (2004) Engineering complex systems. Nature 427: 399

27. Sole R, Goodwin B (2002) Signs of Life: How Complexity Pervades Biology Basic Books, New York, USA.

28. Van Regenmortel MH (2004) Reductionism and complexity in molecular biology. Scientists now have the tools to unravel biological and overcome the limitations of reductionism. EMBO Rep 5: 1016-1020.

29. Van Regenmortel MH (2004) Biological complexity emerges from the ashes of genetic reductionism. J Mol Recognit 17: 145-148.

30. Van Regenmortel MH, Hull DL (2002) Promises and Limits of Reductionism in the Biomedical Sciences (Catalysts for Fine Chemical Synthesis). John Wiley \& Sons, West Sussex. 
31. Greek R (2008) Letter. Dogs, Genes and Drugs. American Scientist 96: 4.

32. Greek R, Hansen LA, Menache A (2011) An analysis of the Bateson Review of research using nonhuman primates. Medicolegal and Bioethics 1: 3-22.

33. Greek R, Shanks N (2009) FAQs About the Use of Animals in Science: A handbook for the scientifically perplexed. University Press of America, Lanham.

34. Greek R, Shanks N, Rice MJ (2011) The History and Implications of Testing Thalidomide on Animals. The Journal of Philosophy, Science \& Law.

35. Shanks N, Greek R (2009) Animal Models in Light of Evolution. Brown Walker Press, Boca Raton.

36. Shanks N, Greek R, Greek J (2009) Are animal models predictive for humans? Philos Ethics Humanit Med 4: 2

37. Jackson J (1868) Observations on the physiology and pathology of hemichorea Edinburgh Med J 14: 294-303.

38. Hunt $R$ (1917) Progressive atrophy of the globus pallidus. A contribution to the functions of the corpus striatum. Brain 40: 58-64.

39. Compston A (2009) Progressive lenticular degeneration: a familial nervous disease associated with cirrhosis of the liver, by S. A. Kinnier Wilson, (From the National Hospital, and the Laboratory of the National Hospital, Queen Square, London) Brain 1912: 34; 295-509. Brain 132: 1997-2001.

40. Bull PC, Thomas GR, Rommens JM, Forbes JR, Cox DW (1993) The Wilson disease gene is a putative copper transporting P-type ATPase similar to the Menkes gene. Nat Genet 5: 327-337.

41. Tanzi RE, Petrukhin K, Chernov I, Pellequer JL, Wasco W, et al. (1993) The Wilson disease gene is a copper transporting ATPase with homology to the Menkes disease gene. Nat Genet 5: 344-350.

42. Wilson S (1914) An experimental research into the anatomy and physiology of the corpus striatum. Brain 36: 427-492.

43. Zulch KJ (1968) Otfrid Foerster, an appreciation (1873-1941). J Neurol Sci 6 : 384-385

44. Tan TC, Black PM (2001) The contributions of Otfrid Foerster (1873-1941) to neurology and neurosurgery. Neurosurgery 49: 1231-1235.

45. Foerster O (1921) Zur Analyse und Pathophysiologie der striaren Bewegungsstorungen. Zeitschr f d ges Neurol u Psychiatr 73: 1-169.

46. Rosenow J, Das K, Rovit RL, Couldwell WT (2002) Irving S. Cooper and his role in intracranial stimulation for movement disorders and epilepsy. Stereotact Funct Neurosurg 78: 95-112.

47. Horsley $\vee(1892)$ On the topographical relations of the cranium and surface of the cerebrum. In: Cunningham DJ (ed) Contribution to the Surface Anatomy of the Cerebral Hemispheres. The Academy House, Dublin: 306-355.

48. Clarke RH, Horsley V (2007) The classic: On a method of investigating the deep ganglia and tracts of the central nervous system (cerebellum). $\mathrm{Br}$ Med J 1906:1799-1800. Clin Orthop Relat Res 463: 3-6.

49. Levy R (1992) A Short History of Stereotactic Neurosurgery. Adapted with permission from: Patrick J. Kelly, MD "Introduction and Historical Aspects" Tumor Stereotaxis Philadelphia: W.B. Saunders Company (1991) and Philip L. Gildenberg, MD, PhD "Stereotactic Surgery: Present and Past" Stereotactic Neurosurgery (Editor: M. Peter Heilbrun) Baltimore: Williams and Wilkins (1988). Cyber Museum of Neurosurgery, October 22.

50. Compston A (2007) The structure and functions of the cerebellum examined by a new method. By Sir Victor Horsley, Clarke RH Brain 1908: 31; 45,Äì124. Brain 130: 1449-1452.

51. Schurr PH, Merrington WR (1978) The Horsley-Clarke stereotaxic apparatus. Br J Surg 65: 33-36.

52. Spiegel EA, Wycis HT, Marks M, Lee AJ (1947) Stereotaxic Apparatus for Operations on the Human Brain. Science 106:349-350.

53. Spiegel EA, Wycis HT (1952) Thalamotomy and pallidotomy for treatment of choreic movements. Acta Neurochir (Wien) 2: 417-422.

54. Spiegel EA, Wycis HT, Szekely EG, Spuler H (1961) Some recent studies of the strio-pallidum and the thalamus in relation to extrapyramidal disorders. Rev Can Biol 20: 351-357

55. Spiegel EA, Wycis HT, Baird HW 3rd (1958) Long-range effects of electropallidoansotomy in extrapyramidal and convulsive disorders. Neurology 8: 734-740.
56. Spiegel EA, Wycis HT, Baird HW 3rd, Szekely EG (1956) Functional state of basal ganglia in extrapyramidal and convulsive disorders; an electrographic study. AMA Arch Neurol Psychiatry 75: 167-174.

57. Spiegel EA, Wycis HT, Szekely EG, Adams DJ, Flanagan M, et al. (1963) campotomy in various extrapyramidal disorders. J Neurosurg 20: 871-884.

58. Spiegel E (1966) Development of stereoencephalotomy for extra-pyramida diseases. J Neurosurg 24: 433-439.

59. Spiegel EA, Wycis HT (1950) Pallidothalamotomy in chorea. Arch Neurol Psychiatry 64: 295-296

60. Spiegel EA, Wycis HT (1952) Thalamotomy and pallidotomy for treatment of choreic movements. Acta Neurochir (Wien) 2: 417-422.

61. Horsley V, Clarke RH (1908) The structure and functions of the cerebellum examined by a new method. Brain 31: 45-124.

62. Ranson S (1934) On the use of the Horsley-Clarke stereotaxic instrument. Psychiat Neurol BI Amst 38: 534-554.

63. Gross CE, Boraud T, Guehl D, Bioulac B, Bezard E (1999) From experimentation to the surgical treatment of Parkinson's disease: prelude or suite in basal ganglia research? Prog Neurobiol 59: 509-532.

64. Bergman H, Wichmann T, DeLong MR (1990) Reversal of experimental parkinsonism by lesions of the subthalamic nucleus. Science 249: 1436-1438.

65. Alexander GE, Crutcher MD, Delong MR (1990) Basal ganglia-thalamocortica circuits: parallel substrates for motor, oculomotor, "prefrontal" and "limbic" functions. Prog Brain Res 85: 119-146.

66. Mitchell IJ, Jackson A, Sambrook MA, Crossman AR (1989) The role of the subthalamic nucleus in experimental chorea. Evidence from 2-deoxyglucose metabolic mapping and horseradish peroxidase tracing studies. Brain 112 $1533-1548$.

67. Aziz TZ, Peggs D, Sambrook MA, Crossman AR (1991) Lesion of the subthalamic nucleus for the alleviation of 1-methyl-4-phenyl-1,2,3,6tetrahydropyridine (MPTP)-induced parkinsonism in the primate. Mov Disord 6: 288-292.

68. Brotchie JM, Mitchell IJ, Sambrook MA, Crossman AR (1991) Alleviation of parkinsonism by antagonism of excitatory amino acid transmission in the medial segment of the globus pallidus in rat and primate. Mov Disord 6: 133-138.

69. Limousin P, Pollak P, Benazzouz A, Hoffmann D, Le Bas JF, et al. (1995) Effect of parkinsonian signs and symptoms of bilateral subthalamic nucleus stimulation. Lancet 345: 91-95.

70. Limousin-Dowsey $P$, Pollak P, Van Blercom N, Krack P, Benazzouz A, et al (1999) Thalamic, subthalamic nucleus and internal pallidum stimulation in Parkinson's disease. J Neurol 246 Suppl 2: ॥42-45.

71. Guridi J, Luquin MR, Herrero MT, Obeso JA (1993) The subthalamic nucleus: a possible target for stereotaxic surgery in Parkinson's disease. Mov Disord 8 : 421-429.

72. Obeso J, Rodriguez M, Gorospe A, Guridi J, Alvarez L, et al. (1997) Surgica treatment of Parkinson's disease. Baillière's clinical neurology 6: 125-145.

73. Williams J (2008) What Makes Science 'Science'? The Scientist 22: 29.

74. Pinkel D (1958) The use of body surface area as a criterion of drug dosage in cancer chemotherapy. Cancer Res 18: 853-856.

75. Rubner M (1883) Uber den Einfluss der Körpergrösse auf Stoff- und Kraftwechsel. Ztschr f Biol 19: 535-568.

76. Alexander GE, DeLong MR, Strick PL (1986) Parallel organization of functionally segregated circuits linking basal ganglia and cortex. Annu Rev Neurosci 9: 357-381.

77. Greek R, Menache A, Rice MJ (2012) Animal models in an age of personalized medicine. Personalized Medicine 9: 47-64.

78. Anschutz O (1910) Hirnoperation bei Hemiathetosis. Berl Klin Wochenschr 47: 1687.

79. Payr O (1921) Case presented before the Medizinische Gesellschaft at Leipzig Miinchen med Wochenschr 68: 1570.

80. Polenow A (1929) Ein neuer Weg zur operativen Behandlung einiger Formen von Hyperkinese. Zentralbl F Chir 56: 1147-1148. 
81. Horsley V (1890) Remarks on the Surgery of the Central Nervous System. Br Med J 2: 1286-1292.

82. Horsley $\vee(1909)$ The Linacre Lecture on the function of the so-called motor area of the brain: Delivered to the Master and Fellows of St. John's College, Cambridge, May 6th, 1909. Br Med J 2: 121-132.

83. Marshall C (1967) Surgery of epilepsy and motor disorders. In: Walker A (ed) A History of Newvlogicnl Surgery. Hafner Publishing Company, New York, USA: 288-305

84. Bucy PC, Case TJ (1937) Athetosis: II-Surgical treatment of unilateral athetosis (comment). Arch Neurol Psychiatry 37: 1017-1018.

85. Nazaroff N (1927) Uber Alkohol injektionen in die kortikale Hirnsubstanz bei Athetose. Zentralbl f Chir 54: 1478-1481.

86. Gabriel EM, Nashold BS Jr (1998) Evolution of neuroablative surgery for involuntary movement disorders: an historical review. Neurosurgery 42: $575-$ 590

87. Laitinen L (1972) Surgical treatment, past and present, in Parkinson's disease. Acta Neurol Scand Suppl 51: 43-58.

88. Spatz H (1927) Physiologie und Pathologie der Stammganglien. In: Bethe A, vonBergman G, Embden G, Ellinger A (eds) Handbuch der normalen und pathologischen Physiologie. Springer, Berlin: 318-412.

89. Dandy W (1966) The Brain. WF Privor Company, Hagerstown.

90. Bucy P, Case T (1939) Tremor. Physiologic mechanism and abolition by surgical means. Arch Neurol Psychiatr 41:721-746.

91. Bucy P (1944) Relation to abnormal involuntary movements In: Bucy P (ed) The Precentral Motor Cortex. University of Illinois Press, Urbana, USA: 395-408.

92. Bucy P, Case T (1937) Athetosis: II-Surgical treatment of unilateral athetosis. Arch Neurol Psychiatry 37: 983-1020.

93. Wilson S (1929) Modern Problems in Neurology. William Wood \& Co, New York, USA.

94. Bucy P, Buchanan D (1932) Athetosis. Brain 55: 479-492.

95. Meyers H (1940) Surgical procedures for postencephalitic tremor with notes of the physiology of the premotor fibres. Arch Neurol Psychiat 44: 455-461.

96. Meyers R (1951) Surgical experiments in the therapy of certain 'extrapyramidal' diseases: a current evaluation. Acta Psychiatr Neurol Suppl 67: 1-42.

97. Meyers R (1968) The surgery of the hyperkinetic disorders. In: Vinken P, Bruyn $\mathrm{G}$ (eds) Diseases of the Basal Ganglia. North-Holland Publishing Co, New York, USA: 844-878.

98. Kopell BH, Rezai AR, Chang JW, Vitek JL (2006) Anatomy and physiology of the basal ganglia: implications for deep brain stimulation for Parkinson's disease. Mov Disord 21: S238-246.

99. Browder J (1947) Parkinsonism, is it a surgical problem? N Y State J Med 47: 2589-2592.

100.Browder $J(1948)$ Section of the fibers of the anterior limb of the internal capsule in parkinsonism. Am J Surg 75: 264-268.

101. King J (1940) Surgical procedure for postencephalitic tremor, with notes on the physiology of premature fibers. Arch Neurol Psychiatry 44: 458.

102. Meyers H (1942) The modifications of alternating tremors, rigidity and festination by surgery of the basal ganglia. Res Publ Assoc Nerv Mem Dis 21: 602-665.

103. Meyers $R$ (1955) Parkinsonism, athetosis and ballism; a report of progress in surgical therapy. Postgrad Med 17: 369-381.

104. Browder J (1947) Parkinsonism, is it a surgical problem? N Y State J Med 47 2589-2592.

105. Cooper IS (1954) Surgical occlusion of the anterior choroidal artery in parkinsonism. Surg Gynecol Obstet 92: 207-219.

106. Cooper IS (1953) Ligation of the anterior choroidal artery for involuntary movements; parkinsonism. Psychiatr Q 27: 317-319.

107.Abbie AA (1934) The Morphology of the Fore-Brain Arteries, with Especial Reference to the Evolution of the Basal Ganglia. J Anat 68: 433-470.
108. Abbie AA (1933) The Blood Supply of the Lateral Geniculate Body, with a Note on the Morphology of the Choroidal Arteries. J Anat 67: 491-521.

109. Cooper IS (1956) An investigation of neurosurgical alleviation of parkinsonism, chorea, athetosis and dystonia. Ann Intern Med 45: 381-392.

110. Cooper IS, Poloukhine N (1955) Chemopallidectomy: a neurosurgical technique useful in geriatric parkinsonians. J Am Geriatr Soc 3: 839-859.

111. Cooper IS (1960) Results of 1,000 consecutive basal ganglia operations for parkinsonism. Ann Intern Med 52: 483-499.

112. Cooper IS (1959) Chemopallidectomy and chemothalamectomy for parkinsonism and dystonia. Proc R Soc Med 52: 47-60.

113. Cooper IS, Bravo G (1958) Chemopallidectomy and chemothalamectomy. J Neurosurg 15: 244-250.

114. Chan DT, Mok VC, Poon WS, Hung KN, Zhu XL (2001) Surgical management of Parkinson's disease: a critical review. Hong Kong Med J 7: 34-39.

115. Parera C, Cooper IS (1960) A modification of the chemopallidectomy guide. $J$ Neurosurg 17: $547-550$

116. Story JL, French LA, Chou SN, Meier MJ (1965) Experiences with subthalamic lesions in patients with movement disorders. Confin Neurol 26: 218-221.

117. Mundinger F (1965) Stereotaxic interventions on the zona incerta area for treatment of extrapyramidal motor disturbances and their results. Confin Neurol 26: 222-230.

118. Fager CA (1968) Evaluation of thalamic and subthalamic surgical lesions in the alleviation of Parkinson's disease. J Neurosurg 28: 145-149.

119. Cooper IS (1981) Twenty-five years of experience with physiological neurosurgery. Neurosurgery 9: 190-200.

120. Wycis HT, Spiegel EA (1952) Ansotomy in paralysis agitans. Confin Neuro 12: $245-246$.

121. Narabayashi H, Okum T (1953) Procaine oil blocking of the globus pallidus for the treatment of rigidity and tremor of parkinsonism: preliminary report. Proc Jpn Acad 29: 134

122. Narabayashi H, Okuma T, Shikiba S (1956) Procaine oil blocking of the globus pallidus. AMA Arch Neurol Psychiatry 75: 36-48.

123. Narabayaslu H, Okuma T (1954) Some contemplations on the role of the globus pallidus in parkinsonism. Brain Nerve: 157-161.

124. Narabayashi H, Okuma T (1953) Procaine oil blocking of the pallidurn in case of athetosis double (preliminary report). Psychiatria et Neurologia Japonica: 672.

125. Fenelon F (1950) Neurosurgery of parkinsonian syndrome by direct intervention on the extrapyramidal tracts immediately below the lenticular nucleus. Communication followed by film showing patient before and after intervention. . Rev Neurol (Paris) 83: 437-440.

126. Guiot G, Brion S (1952) Neurosurgery of choreoathetosic and Parkinsonian syndromes. Sem Hop 28: 2095-2099.

127. Fenelon $F$ (1955) Subpallidal extrapyramidotomy by electrocoagulation in the treatment of dyskinesia; personal technic . Rev Esp Otoneurooftalmol Neurocir 14: 99-104

128. Fenelon F (1955) Neurosurgery of the ansa lenticularis in dyskinesia and Parkinson's disease; principles and technic of own procedure. Sem Hop 31: 1835-1837.

129. Talairach J, Hécaen H, David M, Monnier M, Deajuriaguerra J (1949) Récherches sur la coagulation thérapeutique des structures souscorticales chez l'homme. Rev Neurol (Paris) 81: 4-24.

130. Guiot G, Brion S (1953) Treatment of abnormal movement by pallidal coagulation . Rev Neurol (Paris) 89: 578-580.

131. Svennilson E, Torvik A, Lowe R, Leksell L (1960) Treatment of parkinsonism by stereotatic thermolesions in the pallidal region. A clinical evaluation of 81 cases. Acta Psychiatr Scand 35: 358-377.

132. Whittier JR, Mettler FA (1949) Studies on the subthalamus of the rhesus monkey; hyperkinesia and other physiologic effects of subthalamic lesions: with special reference to the subthalamic nucleus of Luys. J Comp Neurol 90 319-372. 
133. Whittier JR, Mettler FA (1949) Studies on the subthalamus of the rhesus monkey; anatomy and fiber connections of the subthalamic nucleus of Luys. $J$ Comp Neurol 90: 281-317.

134. Wolfson L, Brown LL, Makman M, Warner C, Dvorkin B, et al. (1982) Dopamine mechanisms in the subthalamic nucleus and possible relationship to hemiballismus and other movement disorders. Adv Neurol 35: 203-211.

135. Martin J (1927) Hemichorea resulting from a local lesion of the brain (syndrome of the body of Luys). Brain 50: 637-651.

136. Jakob A (1923) Die extrapyramidalen. Springer, Berlin.

137. Carpenter MB (1955) Ballism associated with partial destruction of the subthalamic nucleus of luys. Neurology 5: 479-489.

138. Guridi J, Obeso JA (1997) The role of the subthalamic nucleus in the origin of hemiballism and parkinsonism: new surgical perspectives. Adv Neurol 74: 235-247.

139. Jakob C (1928) Sindrome de hemibalismo coreifornie cruzado por hemorragia en el nucleo hipotalámico. Arch Argent Neural: 1-15.

140. Martin J, Alcock N (1934) Hemichorea associated with a lesion of the corpus Luysii. Brain: 504-516

141.Dierssen G, Gioino G (1961) Anatomic correlation of hemiballism (on 116 cases published in the literature). Rev Clin Esp 82: 283-305.

142. Lee MS, Marsden CD (1994) Movement disorders following lesions of the thalamus or subthalamic region. Mov Disord 9: 493-507.

143. Carpenter MB, Whittier JR, Mettler FA (1950) Analysis of choreoid hyperkinesia in the Rhesus monkey; surgical and pharmacological analysis of hyperkinesia resulting from lesions in the subthalamic nucleus of Luys. J Comp Neurol 92 293-331.

144.Parkinson J (2002) An essay on the shaking palsy. 1817. J Neuropsychiatry Clin Neurosci 14: 223-236.

145. Bertrand C (1957) The evolution of ideas on the treatment of extra pyramida diseases. Can J Occup Ther 24: 45-50.

146. Alexander GE, Crutcher MD (1990) Preparation for movement: neura representations of intended direction in three motor areas of the monkey. $J$ Neurophysiol 64: 133-150.

147. Alexander GE, Crutcher MD (1990) Functional architecture of basal ganglia circuits: neural substrates of parallel processing. Trends Neurosci 13: 266 271.

148. Alexander GE, Crutcher MD (1990) Neural representations of the target (goal) of visually guided arm movements in three motor areas of the monkey. $J$ Neurophysiol 64: 164-178

149. Parent A, Hazrati LN (1995) Functional anatomy of the basal ganglia. I. The cortico-basal ganglia-thalamo-cortical loop. Brain Res Brain Res Rev 20: 91 127.

150. Parent A, Hazrati LN (1995) Functional anatomy of the basal ganglia. II. The place of subthalamic nucleus and external pallidum in basal ganglia circuitry. Brain Res Brain Res Rev 20: 128-154.

151. Bertrand C, Martinez N (1961) Basal ganglia versus corticospinal tract lesions; their relative importance in the relief of tremor and rigidity. Rev Can Biol 20: 365-375.

152. Guridi J, Lozano AM (1997) A brief history of pallidotomy. Neurosurgery 41 $1169-1180$.

153. Gillingham FJ, Watson WS, Donaldson AA, Naughton JA (1960) The surgical treatment of parkinsonism. Br Med J 2: 1395-1402.

154.Spiegel E, Wycis H (1958) In: Field WS, Thomas CC (eds) Pathogenesis and Treatment of Parkinson's. Springfield: 88-105.

155.Leksell L (1949) A stereotaxic apparatus for intracerebral surgery. Acta Chir Scand 99: 229-233.

156. Laitinen LV (2000) Leksell's unpublished pallidotomies of 1958-1962. Stereotact Funct Neurosurg 74: 1-10

157. Laitinen LV, Bergenheim AT, Hariz MI (1992) Ventroposterolateral pallidotomy can abolish all parkinsonian symptoms. Stereotact Funct Neurosurg 58: 14-21.

158. Laitinen LV, Bergenheim AT, Hariz MI (1992) Leksell's posteroventral pallidotomy in the treatment of Parkinson's disease. J Neurosurg 76: 53-61.
159. Hassler R, Mundinger F, Riechert T (1970) Pathophysiology of tremor at rest derived from the correlation of anatomical and clinical data. Confin Neurol 32 79-87.

160. Hassler R (1950) Anatomy of the thalamus . Arch Psychiatr Nervenkr Z Gesamte Neurol Psychiatr 184: 249-256.

161. Hassler R (1950) Cerebellar projections to the midbrain and thalamus in man Dtsch Z Nervenheilkd 163: 629-671.

162. Hassler R (1949) Nervenartz 20: 537-541.

163. Laitinen LV, Hariz M (1990) Abstracts of the First International Congress of Movement Disorders. Palladial surgery abolishes all Parkinsonian symptoms. Mov Disord 5: 82

164.Bakay RA, DeLong MR, Vitek JL (1992) Posteroventral pallidotomy for Parkinson's disease. J Neurosurg 77: 487-488.

165. Albe Fessard D, Arfel G, Guiot G, Derome P, Dela Herran, et al. (1963) characteristic electric activities of some cerebral structures in man. Ann Chir 17: $1185-1214$

166. Albe-Fessard D, Arfel G, Guiot G, Derome P, Hertzog E, et al. (1966) Electrophysiological studies of some deep cerebral structures in man. J Neurol Sci 3: 37-51.

167. Albe-Fessard D, Arfel G, Guiot G, Derome P, Guilbaud G (1967) Thalamic unit activity in man. Electroencephalogr Clin Neurophysiol.

168. Hutchison WD, Lozano AM, Davis KD, Saint-Cyr JA, Lang AE, et al. (1994) Differential neuronal activity in segments of globus pallidus in Parkinson's disease patients. Neuroreport 5: 1533-1537.

169. Sterio D, BeriÄ $\ddagger A$, Dogali M, Fazzini E, Alfaro G, et al. (1994)Neurophysiologica properties of pallidal neurons in Parkinson's disease. Ann Neurol 35: 586-591.

170.Lozano A, Hutchison W, Kiss Z, Tasker R, Davis K, et al. (1996) Methods fo microelectrode-guided posteroventral pallidotomy. J Neurosurg 84: 194-202.

171. Follett KA, Weaver FM, Stern M, Hur K, Harris CL, et al. (2010) Pallidal versus subthalamic deep-brain stimulation for Parkinson's disease. $\mathrm{N}$ Engl J Med 362: 2077-2091.

172. Riechert T, Krainick JU (1973) Experience with a new combined openstereotactic transsphenoidal operation for pituitary tumors. Dtsch Med Wochenschr 98: 646-649.

173. Riechert T (1973) Newer indications for stereotaxic operations . Z Allgemeinmed 49: 253-256.

174. Riechert T (1965) Stereotaxic operations for extrapyramidal motor disturbances with particular regard to age groups. Confin Neurol 26: 213-217.

175. Mundinger F, Riechert T (1966) Indication and long-term results with 1400 uni- and bilateral stereotaxic operations in Parkinson's syndrome. Wien Z Nervenheilkd Grenzgeb 23: 147-177.

176. Scott RM, Brody JA, Schwab RS, Cooper IS (1970) Progression of unilateral tremor and rigidity in Parkinson's disease. Neurology 20: 710-714.

177.Scott RM, Brody JA (1971) Benign early onset of Parkinson's disease: syndrome distinct from classic postencephalitic parkinsonism. Neurology 21 : 366-368.

178. Scott RM, Brody JA (1970) Benign early-onset Parkinson's disease: a syndrome distinct from classic postencephalitic parkinsonism. Neurology 20 : 400.

179. Scott RM, Brody JA, Cooper IS (1970) The effect of thalamotomy on the progress of unilateral Parkinson's disease. J Neurosurg 32: 286-288.

180. Bertrand G, Oliver A, Thompson CJ (1973) The computerized brain atlas: its use in stereotaxic surgery. Trans Am Neurol Assoc 98: 233.

181. Hassler R, Mundinger F, Riechert T (1979) Stereotaxis in Parkinson's Syndrome. Springer-Verlag, Berlin

182. Andy OJ, Jurko MF, Sias FR Jr (1963) subthalamotomy in treatment of parkinsonian tremor. J Neurosurg 20: 860-870.

183. Andy OJ (1983) Thalamic stimulation for control of movement disorders. App Neurophysiol 46:107-111.

184. Hassler R, Mundinger F, Riechert T (1965) Correlations between clinical and autoptic findings in stereotaxic operations of parkinsonism. Confin Neurol 26 282-290 
185. Narabayashi $\mathrm{H}$ (1982) Generating mechanism and treatment of parkinsonian symptoms . Rinsho Shinkeigaku 22: 1055-1062.

186. Ohye C, Hirai T, Miyazaki M, Shibazaki T, Nakajima H (1982) Vim thalamotomy for the treatment of various kinds of tremor. Appl Neurophysiol 45: 275-280.

187. Kandel E (1989) Functional and Stereotactic Neurosurgery. Plenum

188. Bravo GJ, Cooper IS (1959) A clinical and radiological correlation of the lesions produced by chemopallidectomy and thalamectomy. J Neurol Neurosurg Psychiatry 22: 1-10.

189. Benabid AL, Pollak P, Louveau A, Henry S, De Rougemont J (1987) Combined (thalamotomy and stimulation) stereotactic surgery of the VIM thalamic nucleus for bilateral Parkinson disease. Appl Neurophysiol 50: 344-346.

190. Debru A (2006) The power of torpedo fish as a pathological model to the understanding of nervous transmission in Antiquity. C R Biol 329: 298-302.

191. Kellaway P (1946) The part played by electric fish in the early history of bioelectricity and electrotherapy. Bull Hist Med 20: 112-137.

192. Schwalb JM, Hamani C (2008) The history and future of deep brain stimulation Neurotherapeutics 5: 3-13.

193. Aldini J (1804) Essai théorique et expérimental sur le galvanisme, avec une série d' expériences faites devant des commissaires de l' Institut nationale de France, et en divers amphithéâtres anatomiques de Londres. Fournier Fils, Paris.

194.Parent A (2004) Giovanni Aldini: from animal electricity to human brain stimulation. Can J Neurol Sci 31: 576-584.

195. Rolando L (1809) Saggio sopra la struttura del cervello dell'uomo e degli animali e sopra le funzioni del sistema nervoso. Stamperia Privilegiata Sassari.

196. Sironi VA (2011) Origin and evolution of deep brain stimulation. Front Integr Neurosci 5: 42.

197. Cooper IS (1973) Effect of stimulation of posterior cerebellum on neurological disease. Lancet 1: 1321.

198. Cooper IS (1973) Effect of chronic stimulation of anterior cerebellum on neurological disease. Lancet 1: 206.

199. Medtronics (2011) About Deep Brain Stimulation for Movement Disorders Medtronics Inc, October 27.

200. Bekhtereva NP, Grachev KV, Orlova AN, latsuksl (1963) Utilization of multiple electrodes implanted in the subcortical structure of the human brain for the treatment of hyperkinesis. Zh Nevropatol Psikhiatr Im S S Korsakova 63: 3-8.

201. Bechtereva NP, Bondartchuk AN, Smirnov VM, Meliutcheva LA, Shandurina AN (1975) Method of electrostimulation of the deep brain structures in treatment of some chronic diseases. Confinia neurologica 37: 136-140.

202. Bechtereva NP, Bondartchuk AN, Smirnov VN, Meliutcheva LA (1972) Therapeutic electrostimulation of deep brain structures. Vopr Neirokhir: 7-12.

203. Mclellan D (1982) Cerebellar and deep brain stimulation in movement disorders. In: Marsden C, Fahn S (eds) Movement Disorders. Butterworth London, UK: 334-344.

204. Hassler R, Riechert T, Mundinger F, Umbach W, Ganglberger JA (1960) Physiological observations in stereotaxic operations in extrapyramidal motor disturbances. Brain 83: 337-350.

205. Narabayashi H (1982) Tremor mechanisms. In: Schaltenbrand, Walker (eds) Stereotaxis of the human brain. Thieme Verlag, Stuttgart: 510-514.

206. Narabayashi $H$ (1989) Stereotaxic Vim thalamotomy for treatment of tremor. Eur Neurol 29: 29-32.

207. Mundinger F, Neumuller H (1982) Programmed stimulation for control of chronic pain and motor diseases. Appl Neurophysiol 45: 102-111.

208. Mundinger $F(1977)$ New stereotactic treatment of spasmodic torticollis with a brain stimulation system (author's transl). Med Klin 72: 1982-1986.

209. Cooper IS, Upton AR, Amin I (1982) Chronic cerebellar stimulation (CCS) and deep brain stimulation (DBS) in involuntary movement disorders. Appl Neurophysiol 45: 209-217.

210. Brice J, Mclellan L (1980) Suppression of intention tremor by contingent deepbrain stimulation. Lancet 1: 1221-1222.
211. Nashold B, Slaughter D (1969) Some observations on tremors. In: Gillingham $\mathrm{F}$ (ed) Third symposium on Parkinson's disease. Livingstone: 241-246.

212. Ohye C, Fukamachi A, Miyazaki M, Isobe I, Nakajima H, et al. (1977) Physiologically controlled selective thalamotomy for the treatment of abnormal movement by Leksell's open system. Acta Neurochir (Wien) 37: 93-104.

213. Narabayashi H (1982) Surgical approach to tremor. In: Marsden C, Fahn S (eds) Movement Disorders. Butterworth, London: 292-299.

214. Heath R (1954) Studies in schizophrenia. Harvard University Press, Cambridge.

215. Mazars G, Merienne L, Cioloca C (1980) Control of dyskinesias due to sensory deafferentation by means of thalamic stimulation. Acta Neurochir Suppl (Wien) 30:239-243.

216. Pool J, Clark W, Hudson P, Lombardo M (1956) Hypothalamo-hypophysea interrelationships. Charles $\mathrm{C}$ Thomas, Springfield.

217. Delgado JM, Hamlin H, Chapman WP (1952) Technique of intracrania electrode implacement for recording and stimulation and its possible therapeutic value in psychotic patients. Confin Neurol 12: 315-319.

218. Vercueil L, Krack P, Pollak P (2002) Results of deep brain stimulation for dystonia: a critical reappraisal. Mov Disord 17: S89-93.

219. Benabid AL, Pollak P, Gross C, Hoffmann D, Benazzouz A, et al. (1994) Acute and long-term effects of subthalamic nucleus stimulation in Parkinson's disease. Stereotact Funct Neurosurg 62: 76-84.

220. Benabid AL, Pollak P, Gervason C, Hoffmann D, Gao DM, et al. (1991) Longterm suppression of tremor by chronic stimulation of the ventral intermediate thalamic nucleus. Lancet 337: 403-406.

221. Benazzouz A, Gross C, Feger J, Boraud T, Bioulac B (1993) Reversal of rigidity and improvement in motor performance by subthalamic high-frequency stimulation in MPTP-treated monkeys. The European journal of neuroscience 5: 382-389.

222. Pollak P, Benabid AL, Gross C, Gao DM, Laurent A, et al. (1993) Effects of the stimulation of the subthalamic nucleus in Parkinson disease. Rev Neuro 149: $175-176$

223. Gross RE, Lozano AM (2000) Advances in neurostimulation for movement disorders. Neurol Res 22: 247-258.

224. Siegfried J (1987) Sensory thalamic neurostimulation for chronic pain. Pacing Clin Electrophysiol 10:209-212.

225. Siegfried $\mathrm{J}$ (1986) Effect of stimulation of the sensory nucleus of the thalamus on dyskinesia and spasticity. Rev Neurol 142: 380-383.

226. Giere RN, Bickle J, Mauldin RF (2006) Understanding Scientific Reasonoing Thomson Wadsworth, Toronto.

227. Greek R, Greek J (2010) Is the use of sentient animals in basic research justifiable? Philos Ethics Humanit Med 5: 14.

228. Alm E, Arkin AP (2003) Biological networks. Curr Opin Struct Biol 13: 193-202.

229. Csete ME, Doyle JC (2002) Reverse engineering of biological complexity. Science 295: 1664-1669.

230.Jura J, Wegrzyn P, Jura J, Koj A (2006) Regulatory mechanisms of gene expression: complexity with elements of deterministic chaos. Acta Biochim Pol 53: $1-10$.

231. Morowitz HJ (2002) The Emergence of Everything: How the World Became Complex. Oxford University Press, Oxford.

232. LaFollette $H$, Shanks $N$ (1993) Animal models in biomedical research: some epistemological worries. Public Aff Q 7: 113-130.

233. Lafollette H, Shanks N (1995) Two Models of Models in Biomedical Research Philosophical Quarterly 45: 141-160.

234. Lafollette H, Shanks N (1996) Brute Science: Dilemmas of anima experimentation. Routledge, London and New York.

235. Alam M, Schwabe K, Krauss JK (2011) The pedunculopontine nucleus area: critical evaluation of interspecies differences relevant for its use as a target for deep brain stimulation. Brain 134: 11-23.

236. Defelipe J, Ballesteros-Yanez I, Inda MC, Munoz A (2006) Double-bouquet cells in the monkey and human cerebral cortex with special reference to areas 17 and 18. Prog Brain Res 154: 15-32. 
237. Benabid AL, Torres N (2012) New targets for DBS. Parkinsonism \& related disorders 18: S21-23.

238. Breit S, Schulz JB, Benabid AL (2004) Deep brain stimulation. Cell Tissue Res 318: 275-288.

239. Birdno MJ, Grill WM (2008) Mechanisms of deep brain stimulation in movement disorders as revealed by changes in stimulus frequency. Neurotherapeutics 5 : 14-25.

240. Moran A, Stein E, Tischler H, Belelovsky K, Bar-Gad I (2011) Dynamic stereotypic responses of Basal Ganglia neurons to subthalamic nucleus highfrequency stimulation in the parkinsonian primate. Front Syst Neurosci 5: 21.

241. Wilson CJ, Beverlin B, 2nd, Netoff T (2011) Chaotic desynchronization as the therapeutic mechanism of deep brain stimulation. Front Syst Neurosci 5: 50

242. Rice MJ (2011) The institutional review board is an impediment to human research: the result is more animal-based research. Philos Ethics Humanit Med 6: 12.

243. Ellis LM, Fidler IJ (2010) Finding the tumor copycat. Therapy fails, patients don't. Nat Med 16: 974-975.

244. Marincola FM (2007) In support of descriptive studies; relevance to translational research. J Transl Med 5: 21

245. Uc-Berkeley (2012) Plate Tectonics: The Rocky History of an Idea. February 21

246. Aber JS (2007) Alfred Wegener. Earth Science Department, Emporia State University, February 21.

247. Johnston SC (2006) Translation: case study in failure. Ann Neurol 59: 447 448.

248. Gura T (1997) Systems for identifying new drugs are often faulty. Science 278: $1041-1042$

249. Hahn WC, Weinberg RA (2002) Modelling the molecular circuitry of cancer Nat Rev Cancer 2: 331-341.

250. Rangarajan A, Weinberg RA (2003) Opinion: Comparative biology of mouse versus human cells: modelling human cancer in mice. Nat Rev Cancer 3: 952 959.

251. Anisimov VN, Ukraintseva SV, Yashin Al (2005) Cancer in rodents: does it tell us about cancer in humans? Nat Rev Cancer 5: 807-819.

252. Chabner BA, Roberts TG Jr (2005) Timeline: Chemotherapy and the war on cancer. Nat Rev Cancer 5: 65-72.

253. Gupta S, Sen S (2006) Animal models for heart failure. Methods Mol Med 129: 97-114.

254. Tran P, Hiou-Tim F, Frosst $P$, Lussier-Cacan S, Bagley $P$, et al. (2002) The curly-tail (ct) mouse, an animal model of neural tube defects, displays altered homocysteine metabolism without folate responsiveness or a defect in Mthfr. Mol Genet Metab 76: 297-304.

255. Pangalos MN, Schechter LE, Hurko O (2007) Drug development for CNS disorders: strategies for balancing risk and reducing attrition. Nat Rev Drug Discov 6: 521-532.

256. Enna SJ, Williams M (2009) Defining the role of pharmacology in the emerging world of translational research. Adv Pharmacol 57: 1-30.

257. Kirschner MW, Gerhart JC (2006) The Plausibility of Life. Yale University Press.

258. Grefkes C, Fink GR (2005) Review: The functional organization of the intraparietal sulcus in humans and monkeys. J Anat 207: 3-17.

259. Casanova MF, Trippe J 2nd, Tillquist C, Switala AE (2009) Morphometric variability of minicolumns in the striate cortex of Homo sapiens, Macaca mulatta, and Pan troglodytes. J Anat 214: 226-234.

260. Yasargil M (1969) Microsurgery Applied to Neurosurgery. Academic Press, Germany.

261.Donaghy RMP, Yasargil MG (1968) Microvascular Surgery: Report of 1st Conference. Mosby CV, New York.

262. Broderick JP (2011) The challenges of intracranial revascularization for stroke prevention. N Engl J Med 365: 1054-1055.
263. Chimowitz MI, Lynn MJ, Derdeyn CP, Turan TN, Fiorella D, et al. (2011) Stenting versus aggressive medical therapy for intracranial arterial stenosis. $N$ Engl J Med 365: 993-1003.

264. No authors listed (1985) Failure of extracranial-intracranial arterial bypass to reduce the risk of ischemic stroke. Results of an international randomized trial. The EC/IC Bypass Study Group. N Engl J Med 313: 1191-1200.

265. Powers WJ, Clarke WR, Adams HP Jr, Derdeyn CP, Grubb RL Jr (2012) Commentary: Extracranial-Intracranial Bypass for Stroke in 2012: Response to the Critique of the Carotid Occlusion Surgery Study "It was déjà vu all over again". Neurosurgery 71: E772-E776.

266. Thornton SP (1998) Background of Incisional Refractive Surgery. In: Wu H Thompson V, Steinert R, Hersh P, Slade S (eds) Refractive Surgery. Thieme, New York, USA: 127-134

267. Sato T (1939) Treatment of the conical cornea. Acta Soc Ophthalmol Jpn 544-555.

268. Sato T (1951) Posterior half-corneal incision for myopia (animal experiments) Acta Soc Ophthalmol Jpn 55: 219.

269. Sato T, Akiyama K, Shibata H (1953) A new surgical approach to myopia. Am J Ophthalmol 36: 823-829.

270. Kanai A, Yamaguchi T, Yajima Y, Funahashi M, Nakajima A (1979) The fine structure of bullous keratopathy after anteroposterior incision of the cornea for myopia. Folia Ophthalmol Jpn 30: 841

271. No Author Listed (1981) Radial keratotomy. Am J Ophthalmol 92: 286-295

272. Akiyama K, Tanaka M, Kanai A, Nakajima A (1984) Problems arising from Sato's radial keratotomy procedure in Japan. CLAO J 10: 179-184

273. Weinberger DR (2007) Schizophrenia drug says goodbye to dopamine. Nat Med 13: 1018-1019.

274. Fenster J (2001) Ether Day: The Strange Tale of America's Greatest Medica Discovery and the Haunted Men Who Made It. Harper Collins, New York.

275. Yang L, Sonner JM (2008) Anesthetic-like modulation of receptor function by surfactants: a test of the interfacial theory of anesthesia. Anesth Analg 107 : 868-874.

276. Eckenhoff R, Zheng W, Kelz M (2008) From anesthetic mechanisms research to drug discovery. Clin Pharmacol Ther 84: 144-148.

277.Eckenhoff RG (2008) Why can all of biology be anesthetized? Anesth Analg 107: 859-861.

278. Sedensky MM, Morgan PG (2008) Genetics and the evolution of the anesthetic response. Anesth Analg 107: 855-858.

279. Sonner JM (2008) A hypothesis on the origin and evolution of the response to inhaled anesthetics. Anesth Analg 107: 849-854.

280. Lasagna L (1976) Drug discovery and introduction: regulation and overregulation. Clin Pharmacol Ther 20: 507-511.

281. Beyer KH Jr (1977) Discovery of the thiazides: where biology and chemistry meet. Perspect Biol Med 20: 410-420.

282. Rothwell PM (2006) Funding for practice-oriented clinical research. Lancet 368: $262-266$

283. Institute of Medicine (2011) Chimpanzees in Biomedical and Behaviora Research: Assessing the Necessity. National Academies Press, Washington DC.

284. Martin C (2008) Experimental use of nonhuman primates is not a simple problem. Nat Med 14: 807-808

285. Giles J (2006) Animal experiments under fire for poor design. Nature 444: 981

286. Collins FS (2011) Reengineering Translational Science: The Time Is Right Science Translational Medicine 3: 90.

287. Cook N, Jodrell DI, Tuveson DA (2012) Predictive in vivo animal models and translation to clinical trials. Drug Discov Today 17: 253-260.

288. Dixit R, Boelsterli U (2007) Healthy animals and animal models of human disease(s) in safety assessment of human pharmaceuticals, including therapeutic antibodies. Drug Discov Today 12: 336-342.

289. Drake lii DR, Singh I, Nguyen MN, Kachurin A, Wittman V, et al. (2012) In Vitro Biomimetic Model of the Human Immune System for Predictive Vaccine Assessments. Disruptive Science and Technology 1: 28-40. 
290.FDA (2006) FDA Issues Advice to Make Earliest Stages Of Clinical Drug Development More Efficient. FDA, March 7.

291. Fletcher AP (1978) Drug safety tests and subsequent clinical experience. J R Soc Med 71: 693-696.

292. Heywood R (1990) Clinical Toxicity--Could it have been predicted? Postmarketing experience. In: CE Lumley, Walker S (eds) Animal Toxicity Studies: Their Relevance for Man. Quay, Lancaster: 57-67.

293. Horrobin DF (2003) Modern biomedical research: an internally self-consistent universe with little contact with medical reality? Nat Rev Drug Discov 2: 151 154.

294. Kola I, Landis J (2004) Can the pharmaceutical industry reduce attrition rates? Nat Rev Drug Discov 3: 711-715.

295. Lumley C (1990) Clinical toxicity: could it have been predicted? Premarketing experience. In: Lumley C, Walker S (eds) Animal Toxicity Studies: Their Relevance for Man. Quay: 49-56.

296. M.E. (2010) In This Issue. Models that better mimic human cancer. Nature Biotechnology 28:vii.

297. Markou A, Chiamulera C, Geyer MA, Tricklebank M, Steckler T (2009) Removing obstacles in neuroscience drug discovery: the future path for animal models. Neuropsychopharmacology 34: 74-89.

298. O'collins VE, Macleod MR, Donnan GA, Horky LL, Van Der Worp BH, et al. (2006) 1,026 experimental treatments in acute stroke. Ann Neurol 59: 467477.

299. Sharp PA, Langer R (2011) Promoting Convergence in Biomedical Science. Science 333: 527

300. Sietsema WK (1989) The absolute oral bioavailability of selected drugs. Int $J$ Clin Pharmacol Ther Toxicol 27: 179-211.

301.Suter K (1990) What can be learned from case studies? The company approach. In: Lumley C, Walker S (eds) Animal Toxicity Studies: Their Relevance for Man. Quay, Lancaster: 71-78.

302.Wall RJ, Shani M (2008) Are animal models as good as we think? Theriogenology 69: 2-9.

303. Weaver JL, Staten D, Swann J, Armstrong G, Bates M, et al. (2003) Detection of systemic hypersensitivity to drugs using standard guinea pig assays. Toxicology 193: 203-217.

304.Zielinska E (2010) Building a better mouse. The Scientist 24: 34-38.

305. Wikipedia (2012) Binary Classification. Wikipedia, August 9.

306. Wikipedia (2012) Sensitivity and Specificity. Wikipedia, August 9

307. Wikipedia (2012) Positive predictive value. August 9

308. Buzoni-Gatel D, Decelle T, Hardy P, Montagutelli X, Louis J (2011) Animal Models and Relevance/Predictivity: how to better leverage the knowledge of the veterinarian field. Fondation Mérieux, October 6.

309. Rudczynski AB (2011) Letter. In: New Haven Register. New Haven.

310. Curry SH (2003) Why have so many drugs with stellar results in laboratory stroke models failed in clinical trials? A theory based on allometric relationships. Ann N Y Acad Sci 993: 69-74.

311. Ringach D (2011) Predictions and Animal Models of Human Disease. Speaking of research, August 9.

312. Ringach DL (2011) The use of nonhuman animals in biomedical research. Am J Med Sci 342: 305-313

313. Orac (2010) Answering "scientific" arguments of animal rights extremists. In Respectful Insolence. Science Blogs.

314.Gorski D (2008) Bad scientific arguments in the service of animal rights activism. In: Gorski D, Novella S (eds) Science-Based Medicine. ScienceBased Medicine.

315. Greek R, Pippus A, Hansen LA (2012) The Nuremberg Code subverts human health and safety by requiring animal modeling. BMC Med Ethics 13: 16.

316. Greek R, Shanks N (2011) Complex systems, evolution, and animal models Stud Hist Philos Biol Biomed Sci 42: 542-544.

317. Committee on Revising Science and Creationism (2008) Science, Evolution, and Creationism. National Academy of Sciences, Washington DC.
318. Leaf C (2004) Why we are losing the war on cancer. Fortune: 77-92.

319. Grant J, Green L, Mason B (2003) From Bedside to Bench: Comroe and Dripps Revisited. In: HERG Research Report No. 30 Health Economics Research Group. Brunel University, Uxbridge, Middlesex UB8 3PH, UKPMCID.

320. Smith R (1987) Comroe and Dripps revisited. Br Med J (Clin Res Ed) 295 1404-1407.

321. Crowley WF, Jr. (2003) Translation of basic research into useful treatments: how often does it occur? Am J Med 114: 503-505

322. Butler D (2008) Translational research: crossing the valley of death. Nature 453: $840-842$

323. Begley S (2003) Financial Obstacles Help Keep Doctors From Patient Research. In: Wall Street Journal.

324.Steinman R, Szalavitz M (2002) Patients Have Been Too Patient With Basic Research. Cerebrum.

325. Begley S (2003) Physician-Researchers Needed To Get Cures Out of Rat's Cage. In: Wall Street Journal.

326. NIH Mission Statement.

327. UK Clinical Research Collaboration (2006) UK Health Research Analysis. In, London.

328. Nathan DG, Schechter AN (2006) NIH support for basic and clinical research: biomedical researcher angst in 2006. JAMA 295: 2656-2658

329. Sung NS, Crowley WF, Jr., Genel M, Salber P, Sandy L, et al. (2003) Centra Challenges Facing the National Clinical Research Enterprise. JAMA 289: 1278-1287.

330. Hampton T (2006) Targeted cancer therapies lagging: better trial design could boost success rate. JAMA 296: 1951-1952.

331. Rosenberg RN (2003) Translating biomedical research to the bedside: a national crisis and a call to action. JAMA 289: 1305-1306.

332. Committee on Models for Biomedical Research Board on Basic Biology (1985) Committee on Models for Biomedical Research. Board on Basic Biology. Commission on Life Science. National Research Council. Models for Biomedical Research: A New Perspective. National Academy Press. Washington, DC

333.Panksepp J (1998) Affective Neuroscience: The Foundations of Human and Animal Emotions (Series in Affective Science) Oxford University Press London.

334. Panksepp J (2003) At the interface of the affective, behavioral, and cognitive neurosciences: decoding the emotional feelings of the brain. Brain Cogn 52 $4-14$

335. Panksepp J (2005) Toward a science of ultimate concern. Conscious Cogn 14: 22-29.

336. Panksepp J (2005) Affective consciousness: Core emotional feelings in animals and humans. Conscious Cogn 14: 30-80.

337. Panksepp J, Burgdorf J, Beinfeld MC, Kroes RA, Moskal JR (2004) Regional brain cholecystokinin changes as a function of friendly and aggressive social interactions in rats. Brain Res 1025: 75-84.

338. Panksepp J, Nocjar C, Burgdorf J, Panksepp JB, Huber R (2004) The role of emotional systems in addiction. A neuroethological perspective. In: Bevins RA (ed) 50th Nebraska Symposium on Motivation. Motivational factors in the etiology of drug abuse Lincoln, NE: 85-126.

339. Panksepp JB, Huber R (2004) Ethological analyses of crayfish behavior: a new invertebrate system for measuring the rewarding properties of psychostimulants. Behav Brain Res 153: 171-180.

340. Baldwin A, Bekoff M (2007) Too Stressed to Work. New Scientist: 24

341.Bekoff M (2010) The Animal Manifesto: Six Reasons for Expanding Ou Compassion Footprint. New World Library, California.

342. Bekoff M (2007) Aquatic animals, cognitive ethology, and ethics: questions about sentience and other troubling issues that lurk in turbid water. Dis Aquat Organ 75: 87-98.

343. Bekoff M (2007) Are You Feeling What I'm Feeling? New Scientist: $42-47$

344.Broom DM (2007) Cognitive ability and sentience: which aquatic animals should be protected? Dis Aquat Organ 75: 99-108. 
Citation: Greek R, Hansen LA (2012) The Development of Deep Brain Stimulation for Movement Disorders. J Clinic Res Bioeth 3:137. doi:10.4172/21559627.1000137

Page 21 of 21

345. No authors listed (2009) A slippery slope. Nature 462: 699.

346. Eceae (2012) 12 Million Reasons. European Coalition to End Animal Experiments, August 4.

347.Pew/Aaas (2009) Scientific Achievements Less Prominent Than a Decade Ago. Public praises science; scientists fault public, media. Pew Research Center, July 9.

348. Aldhous P, Coghlan A, Copley J (May 22, 1999) Let the people speak. New Scientist.

349. Organisation for Economic Cooperation and Development (1963) The Measurement of Scientific and Technical activities: Proposed Standard Practice for Surveys of Research and Development. Paris.

350. Understanding Animal Research (2012) Parkinson's disease. Understanding Animal Research, February 16.

351. Montgomery E, Basso MA (2011) Animal Models of Dystonia - Part II. Speaking of Research, February 16.

352. Speaking of Research (2012) Facts. Speaking of Research, February 16.

353. Neurophilosophy (2012) Neurosurgeon condones vivisection for cosmetics. Neurophilosophy, February 16.

354. Tan S, Vlamings R, Lim L, Sesia T, Janssen ML, et al. (2010) Experimental deep brain stimulation in animal models. Neurosurgery 67: 1073-1079.
355. Swerdlow NR, Sutherland AN (2005) Using animal models to develop therapeutics for Tourette Syndrome. Pharmacol Ther 108: 281-293.

356. Animalresearch.Info (2004) Parkinson's Disease. AnimalResearch.info, February 16.

357. Rothwell PM (2006) Medical academia is failing patients and clinicians. BM 332:863-864

358. Brennan R, Federico S, Dyer MA (2010) The war on cancer: have we won the battle but lost the war? Oncotarget 1: 77-83.

359.Pan A, Sun Q, Bernstein AM, Schulze MB, Manson JE, et al. (2012) Red Meat Consumption and Mortality: Results From 2 Prospective Cohort Studies. Arch Intern Med: archinternmed.2011.2287.

360. Coghlan A (2012) 'Western cancers' spreading to developing world. New Scientist, August 5.

361. Bray F, Jemal A, Grey N, Ferlay J, Forman D (2012) Global cancer transitions according to the Human Development Index (2008-2030): a population-based study. Lancet Oncol 13: 790-801.

362. Ledford $H$ (2008) Translational research: the full cycle. Nature 453: 843-845.

363. Medawar P (1993 (1963)) Is the scientific paper a fraud? In: Medawar P (ed) The Strange Case of the Spotted Mice. Oxford University Press, Oxford: 3339. 